
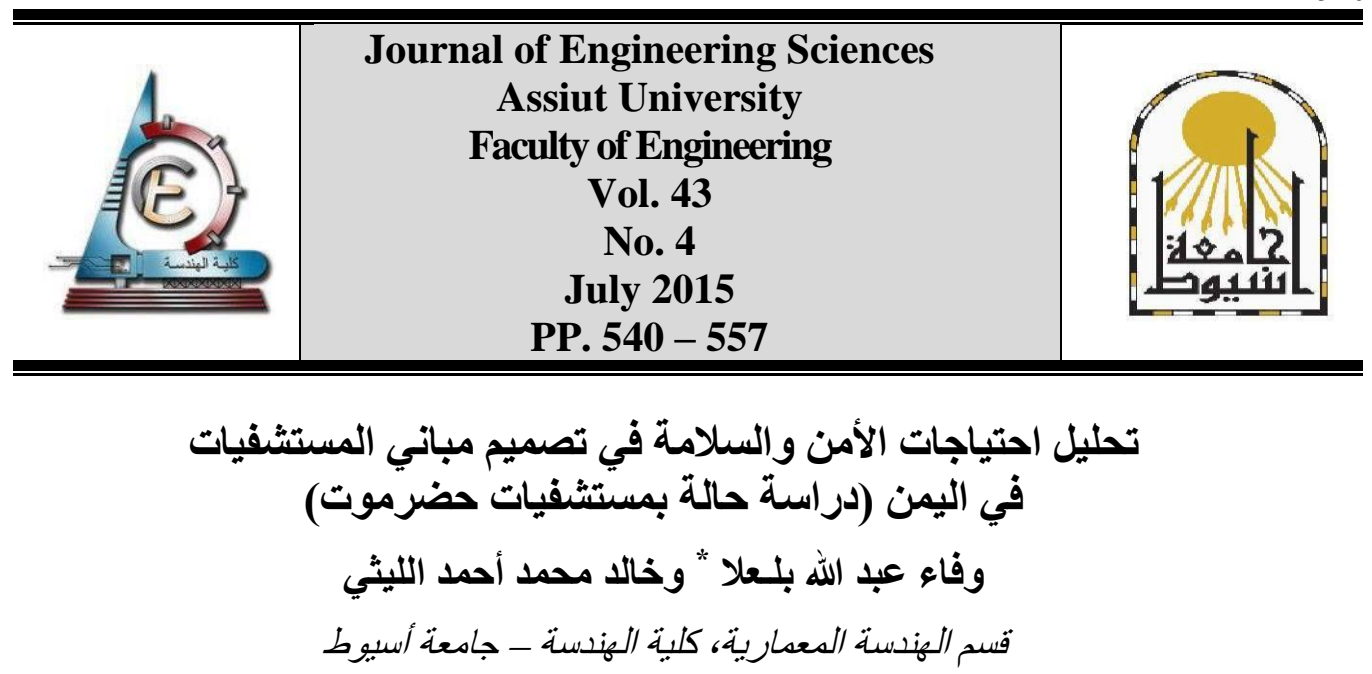

(Received 28 May 2015; Revised 16 June 2015; Accepted 1 July 2015)

الملخ: مص

تناقش الورقة البحتية أهمية توفر احتياجات الأمن والسلامة كأحد المعايير الأساسية لتصميم وتشغيل مباني المنشآت

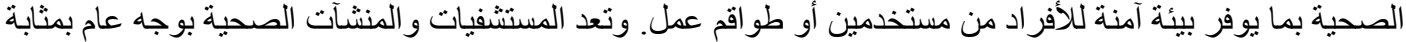

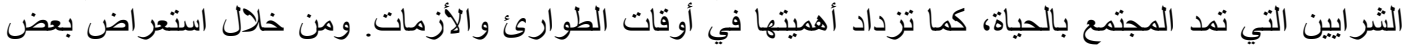

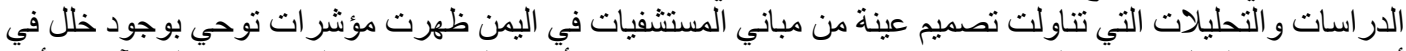

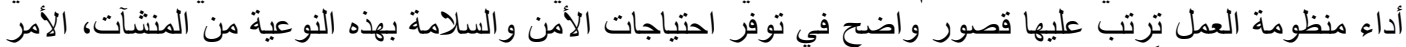
الذي بدوره يؤثر سلباً على سلامة الأفر اد من مرضنى أو زو فورار وكذللك طو اقم العمل المختلفة الطبية أو الفنية أو الإدارية. وتهدف الورقة البحثية إلى التعرف على مدى توفر عناصر الأمن و السلامة في تصميم هذه النوعية من المنشآت كأحد

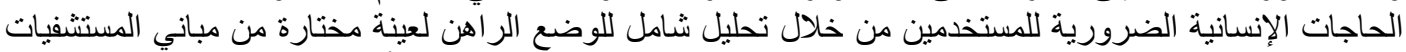

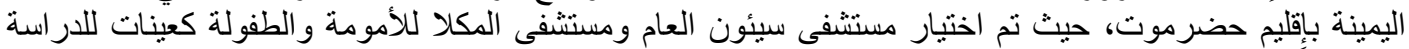

استرشاداً بمعايير الأمن و السلامة المدرجة من فبل منظمة الصحة العالمية (World Health Organization-WHO).

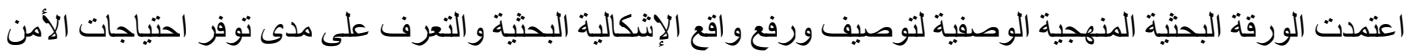

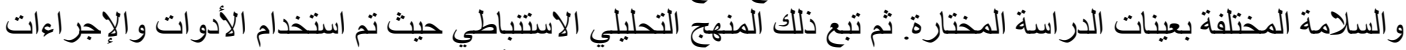

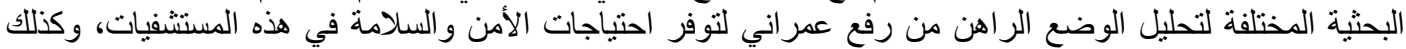

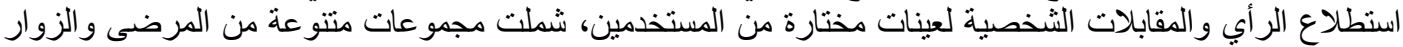

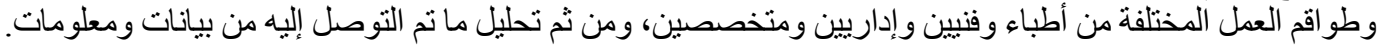
وتحاول الورقة البحتية من خلال هذه التحليلات التوصل إلى تحديد دقيق لمواطن الخلل أو القصور وتحليل المشكلات

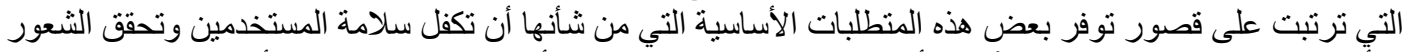

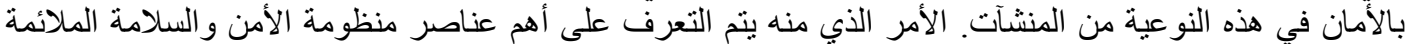

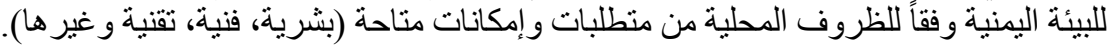

وتخلص الورقة البحثية إلى وضع تصور شامل للعناصر الرئيسية والمتطلبات الضرورية التي يمكن من خلالها تلبية

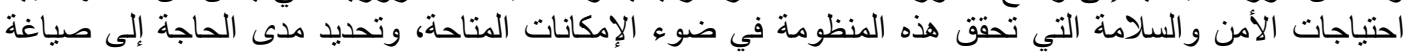

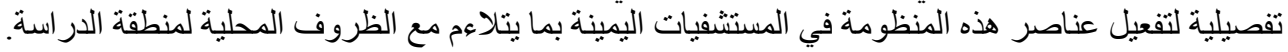
الكلمات المفتاحيةّ: الأمن و السلامة، تصميم المستشفيات، المنشآت الصحية، حضرموت، منظمة الصحة العالمية (WHO).

* Corresponding author.

Email address: waflab006@yahoo.com 


\section{1المقدمة}

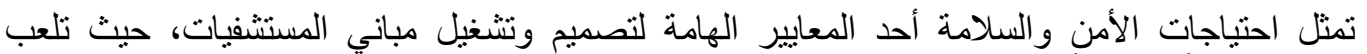

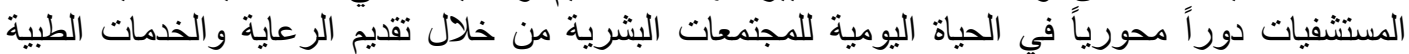

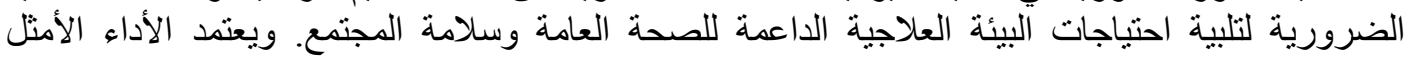

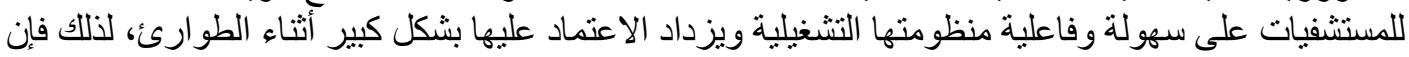

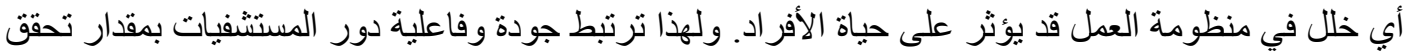

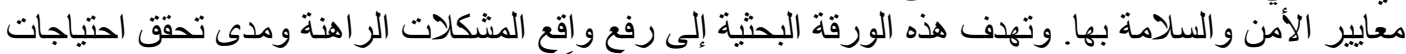

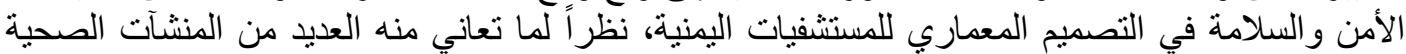
و مباني المستشفيات بمحافظة حضرموت من قصور في توفر معايير و اضحة للأمن و السلامة في هذه المنشآت.

وبالر غم من أهمية مباني المستشفيات إلا إنه لا تظهر استراتيجية واضحة في اليمن لتوفير منظومة

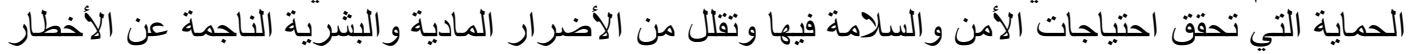

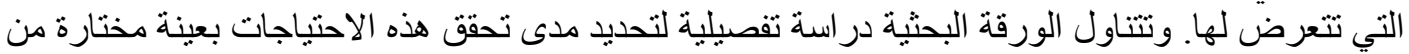

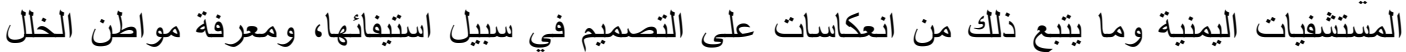
و أوجه القصور والمشكلات الناجمة عنها باعتبار أن الأمن والسلأمة هي الني أهم الحاجات الإنسانية الأساسية

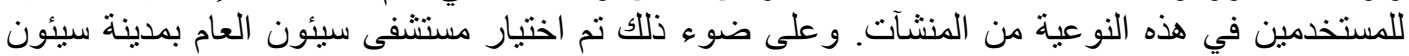

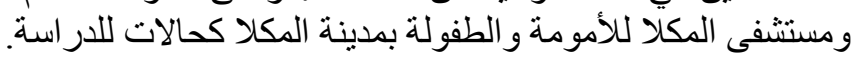

\section{1. الإشكالية البحثية}

تَظهر الإشكالية البحثية من خلال استعر اض بعض الدراسات والتحليلات التي تتاولت تصميم عينة من مباني المستشفيات بمحافظة حضرموت_اليمن (تم اختيار مستشفى سيئون العام بمدينة سيئون ومستشفى الإنى

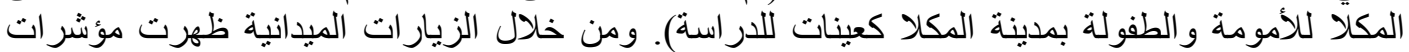

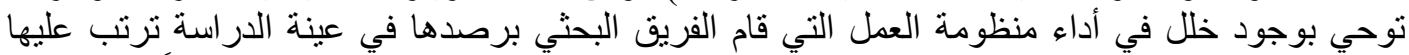

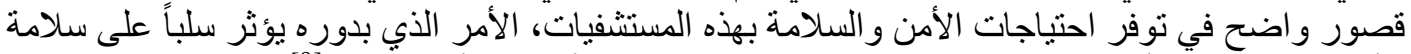

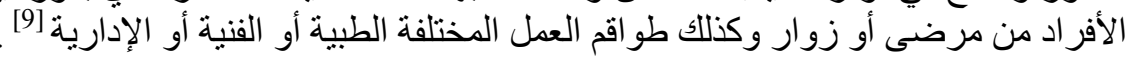

وقد أظهرت نتائج التحليلات تعرّض المستشفيات في هذه المنطقة لمجمو عة من المخاطر الفنية والطبيعية

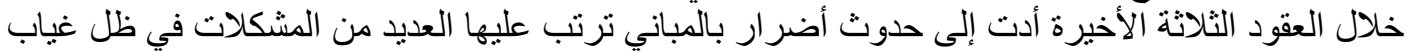

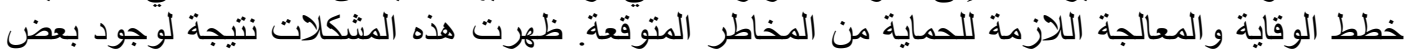

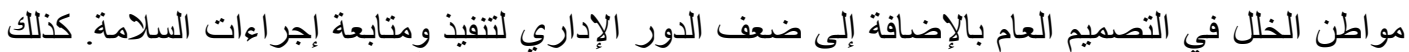

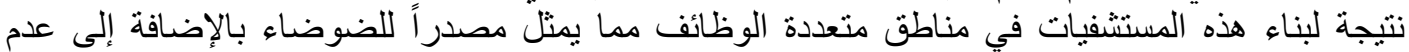

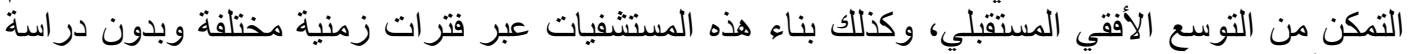
مسبقة أدى إلى ظهور خلل في توزيع الوظائف بالموقع. وتتلخص مظاه الاهر هذا القصور فيما يلي:

• وجود خلل في بعض المناطق الأمنية للتحكم في هذه المسنشفيات تتمثل في نقاط التحكم في المداخل

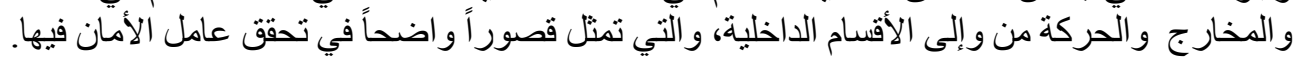

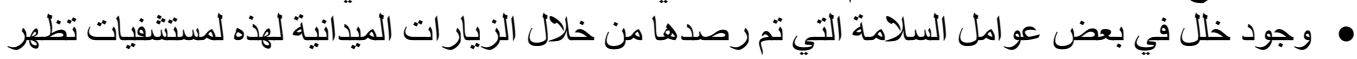

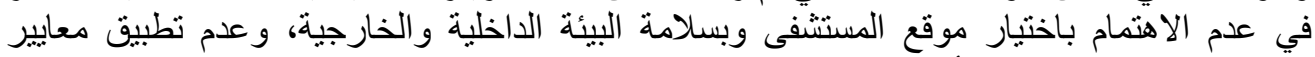

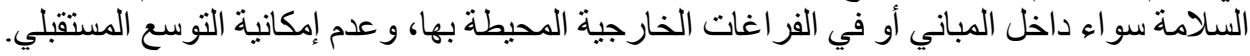
ظهور بعض الإجراءات التصميمية الخاطئة في توزيع الفراغات الوظيفية بمستشفيات مدينة المئية المكلا

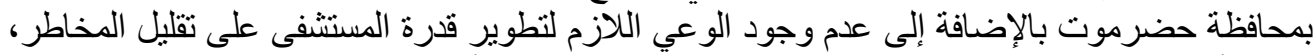

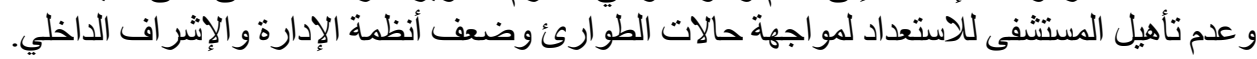


• زيادة خطر العدوى في مباني المستشفيات والذي يتبين من خلال عدم ظهور إجراءات وسياسات

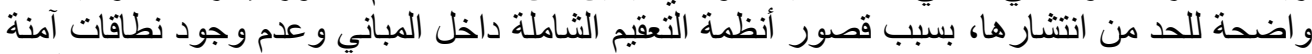

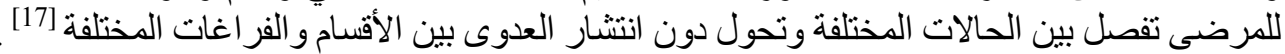

ومن خلال تحليل الوضع الر اهن لحالات الدراسة المختارة بهذه الورقة البحثية سيتم التعرض لهذه النقاط تفصيلاً.

$$
\text { 2.1 }
$$

من خلال تحديد الإشكالية البحثية ورصد الواقع الذي تعاني منه البيئة العلاجية بمباني مستشفيات إقليم

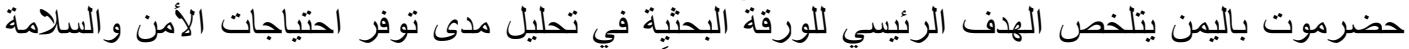

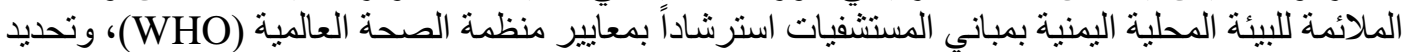

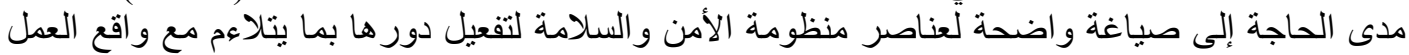
في مستشفيات منطقة الدر اسة.

$$
\text { 3.1. منهجبية البحث }
$$

تعتمد المنهجية البحثية المتبعة للتعامل مع الإشكالية على المنهج الوصفي الذي يركز على توصيف دقيق

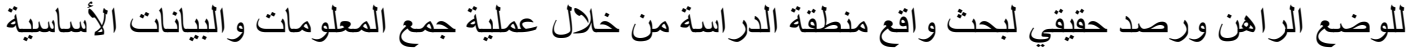

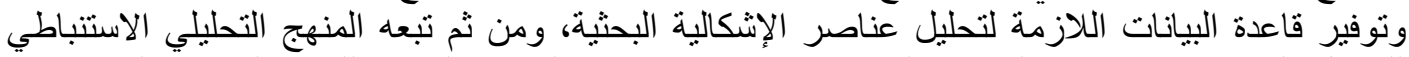

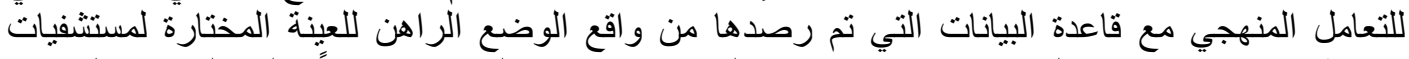

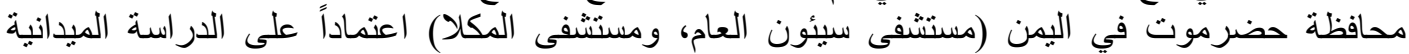

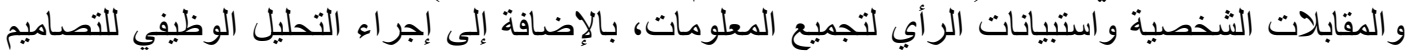

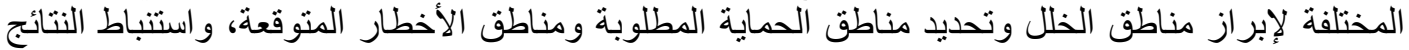

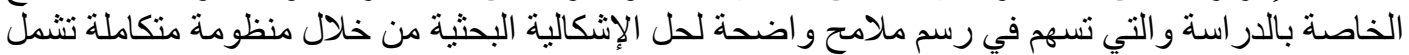
احتباجات الأمن و السلامة الملائمة لمتطلبات و وإمكانات منطقة الدر اسة.

\section{2. منظومة الأمن والسلامة في مباني المستثفيات}

اعتمدت منظمة الصحة العالمية (WHO) مجموعة من المعايير والاشتر اطات التي يجب تو افرها في

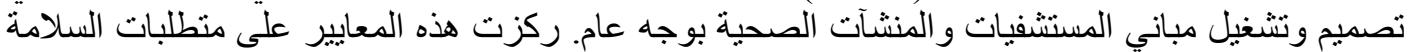

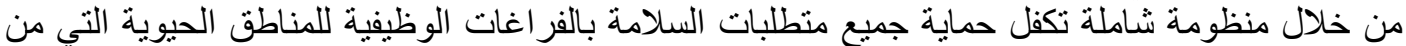

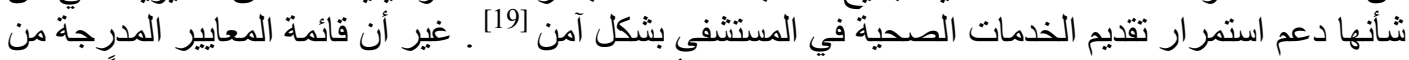

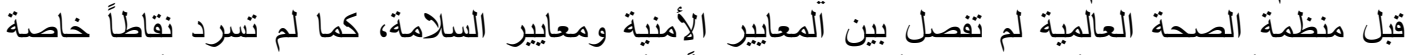

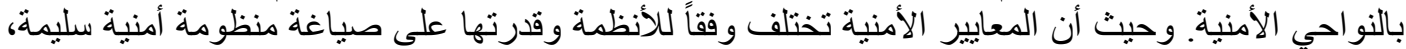

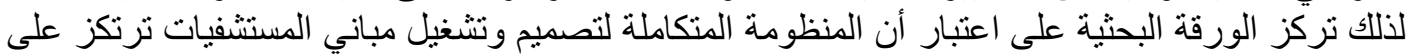

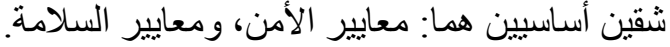

وتركز الورقة البحثية في تناولها للإشكالية وتحليلاتها المنهجية لتقييم مدى تحقق احتياجات الأمن

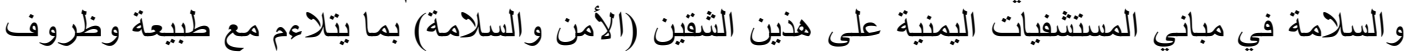

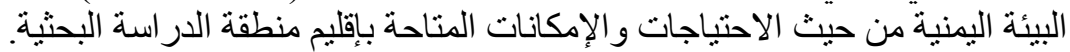

$$
\text { 1.2. احتباجات الأمن في مباني المستشفبات }
$$

تختلف القضايا الأمنية في المستشفى باختلاف احتياجات الفر اغات الوظيفية والتي تهدف مجنمعة إلى توفير بيئة

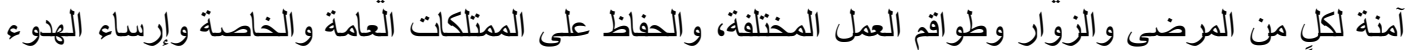
و النظام فِي أرجاء المستشفى وملحقاتها، ويوضح شكل (1) مناطق القلق الأمنية في تصميم مباني المستشفيات. للتلك فمن الضروري توفير الاستعدادات وتطوير الإجراءات الأمنية لتوفير الحماية من خلال دمج الاحتياجات

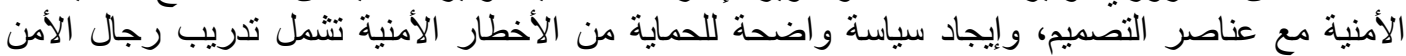


و الموظفين، و التحكم في المداخل، وتحديد نطاقات التتقل والحركة، ونوع المراقبة المستخدمة، إضافة إلى حماية

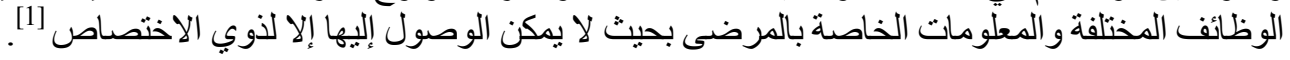

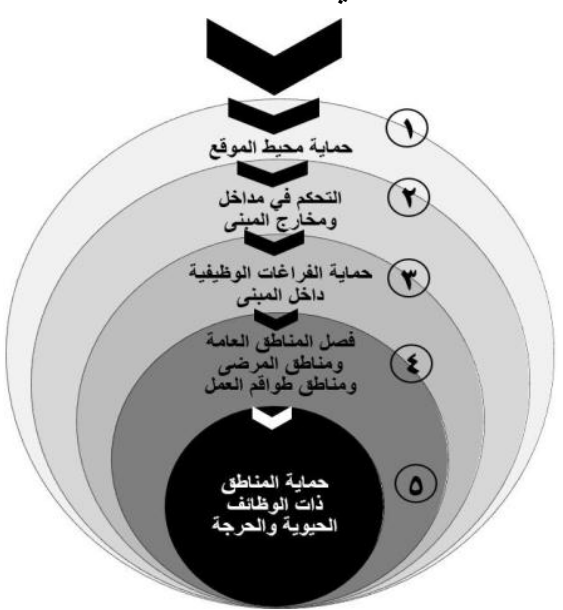

مباني المستشفيات [15): شسلسل النطاقات الأمنية في تصميم

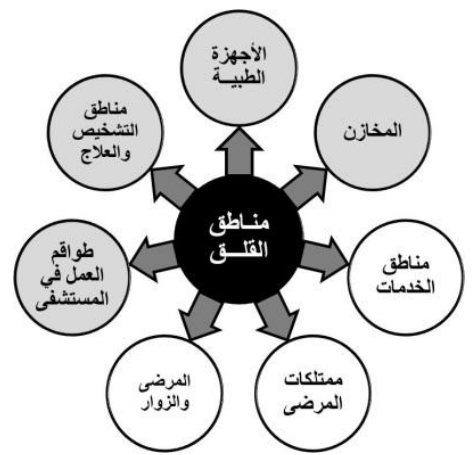

شكل (1): مناطق القلق الأمنية

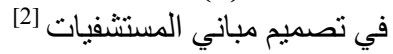

ويعتمد تطوير المبادئ التوجيهية للتصميم الأمني من خلال توفير مستويات من المر اقبة و الحماية للمرضى في إنى

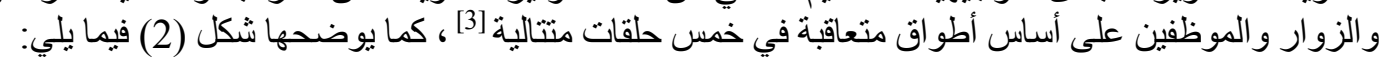

• التحكم في مداخل المبنى وتتمل الأبواب و النوافذ وأجهزة التحكم في الوصول وأي عناصر أخرى للحماية.

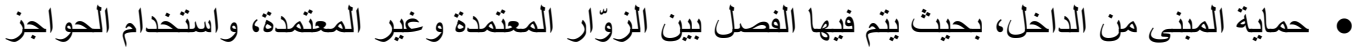

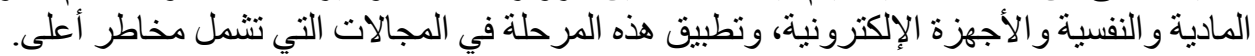

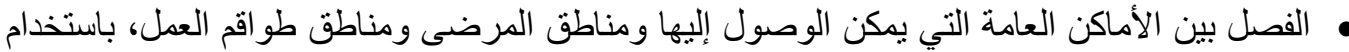

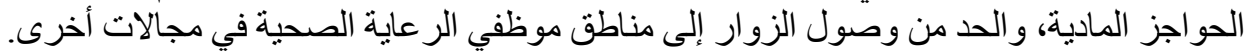

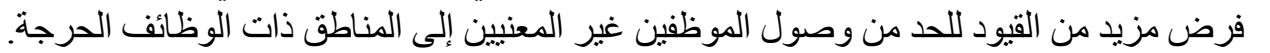

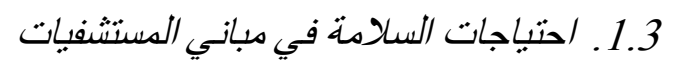

تتمثل المتطلبات الأساسية لتحقيق السلامة للأفر اد في توفير نظام متكامل بشمل حماية الوظائف و المناطق

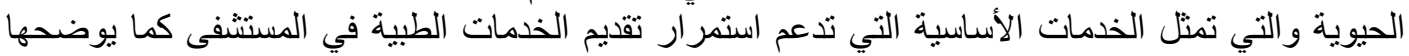

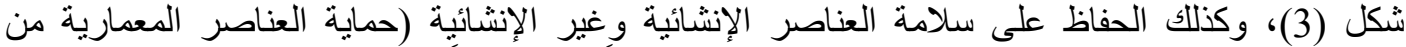

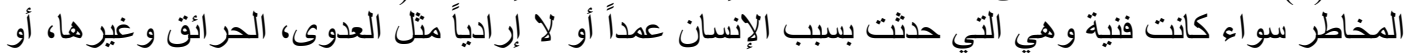

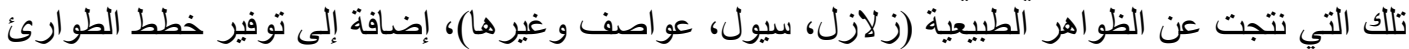

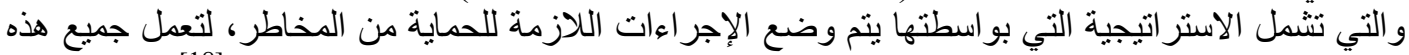

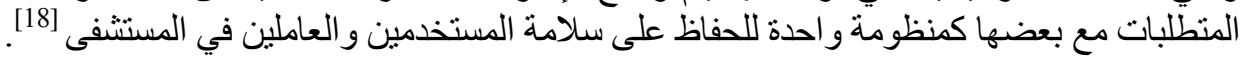

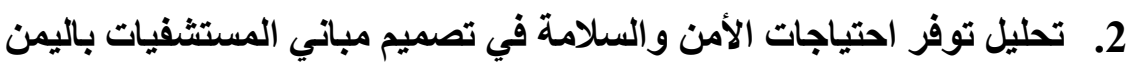

من خلال استعر اض بعض الدراسات و التحليلات التي تناولت تصميم عينة من مباني المستشفيات في

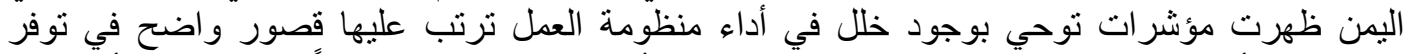

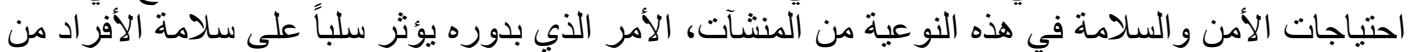
مرضى أو زوار وكذلك طو اقم العمل المختلفة الطبية أو الفنية أو الإدارية. 


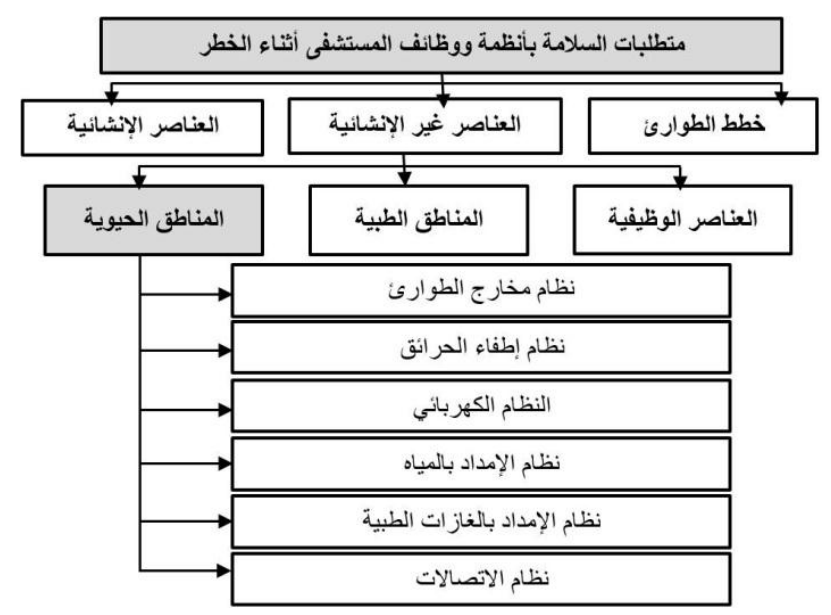

شكل (3): احتياجات ومتطلبات أنظمة تصميم ونتشغيل المستشفى لضمان سلامة الأداء الوظيفي [5]

1.2. الأدوات البحثبة والإجراء/ت المنهجية المتبعة لتحلبل واقع عبنات الدراسة

اعتمدت الورقة البحثية المنهجية الوصفية لتوصيف ورفع واقع الإشكالية البحثية والتعرف على مدى توفر

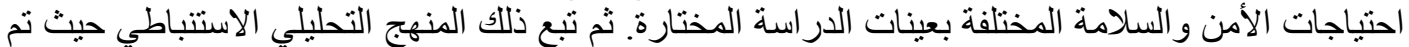

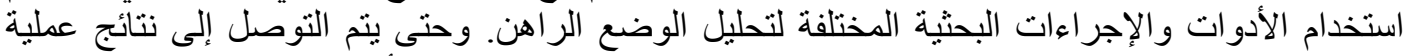

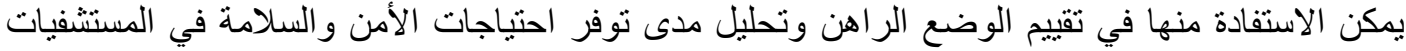

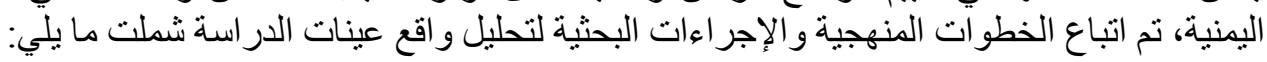

- - تجميع البيانات والمعلومات اللازمة لتكوين قاعدة بيانات و اقعية تمثل ركيزة للتعامل مع الإشكالية البحثية.

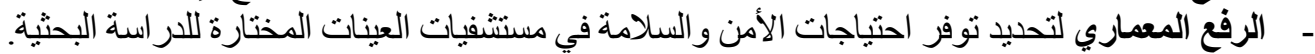

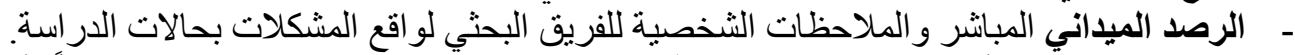

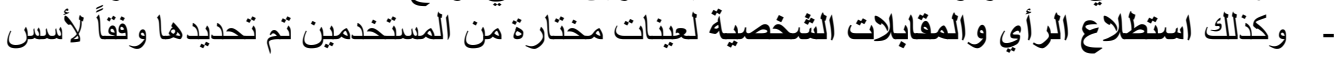

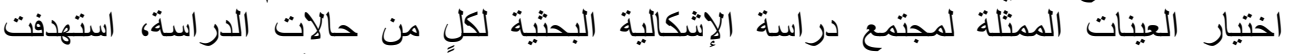

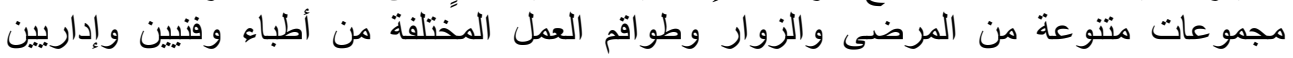

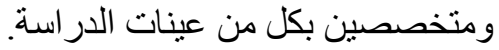
ـ ومن ثم تحليل جميع ما تم التوصل إليه من بيانات ومعلومات ونتائج استبيانات حتى يمكن وضع تصور اتجاهات و اقعية لحل إنكالية الدر استة البحت البحثية.

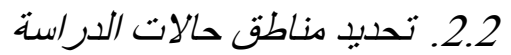
تم اختيار إقليم حضرموت كمنطقة للار اسة حيث يعد أحد الأقاليم الهامة باليمن، فمحافظة حضرموت أكبر

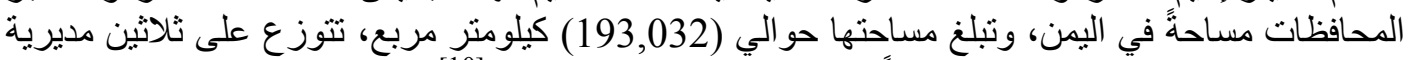

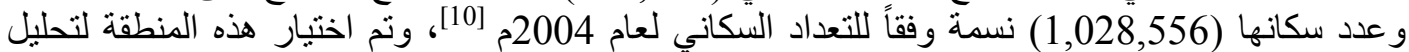
وتقييم الوضع الر اهن لمدى توفر احتياجات الأمن و السلامة بمباني الماني المستشفيات اليمنية.

وبدر اسة ظروف الإقليم و التعرف على توزيع المنشآت الصحية ومباني المستشفيات به تم اختيار مدينتي

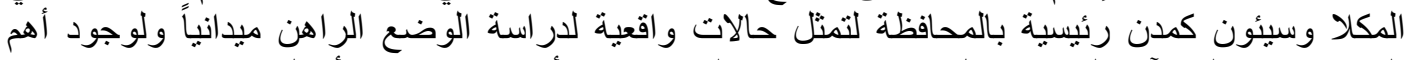

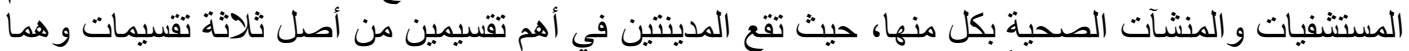

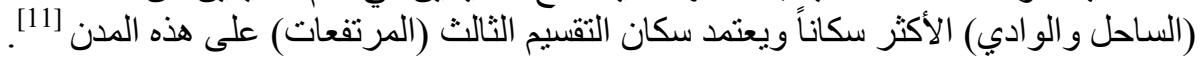

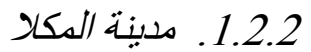

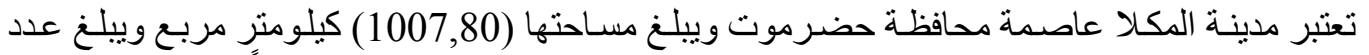

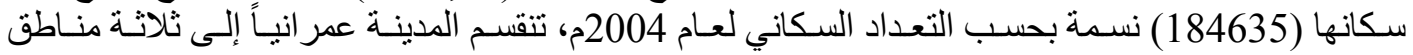


رئيسية؛ المنطقة الثرقية، المنطقة الوسطى، و المنطقة الغربية. وتحتوي المدينة على مستشفيين فقط، مستشفى

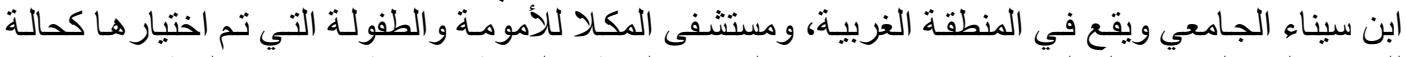

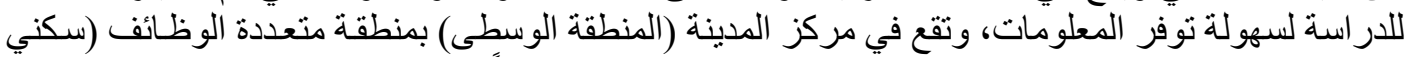

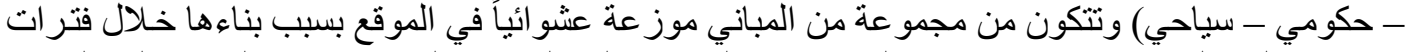

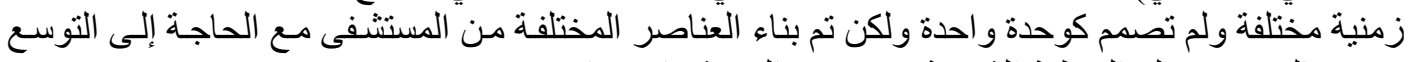
بمرور الزمن. وتخلو المنطقة الثرقية من وجة ودود المستشفيات بها.

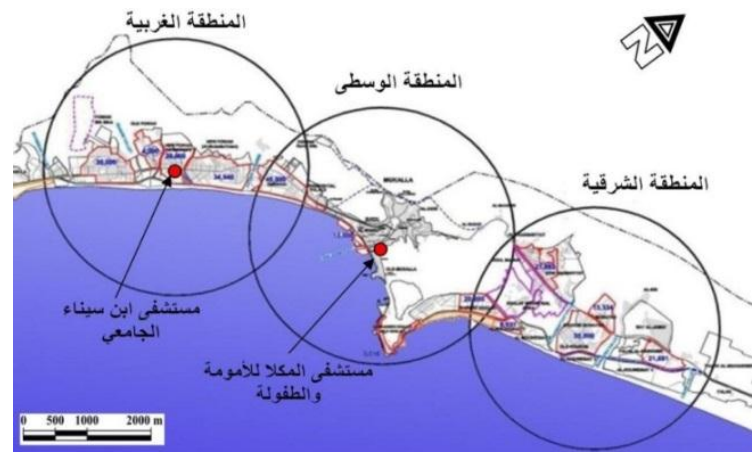

شكل(4): يوضح التقسيمات العمر انية لمدينة المكلا وموقع المستشفيات المختارة فيها [12]

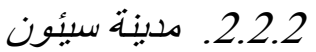

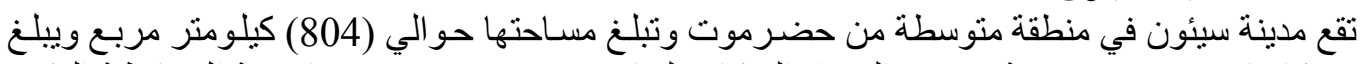

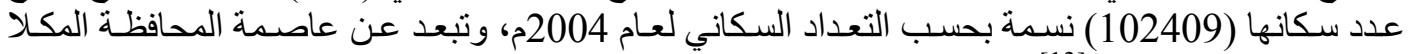

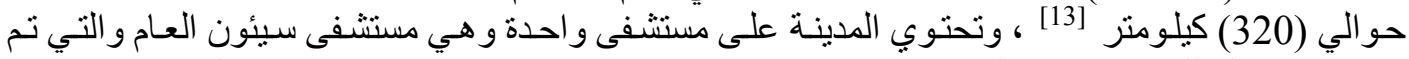

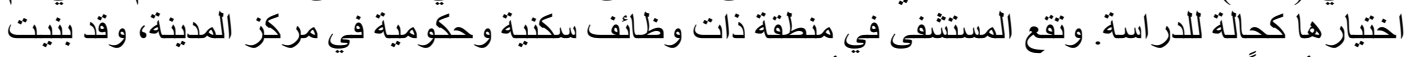

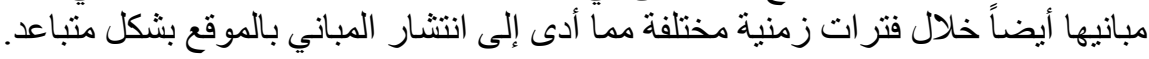

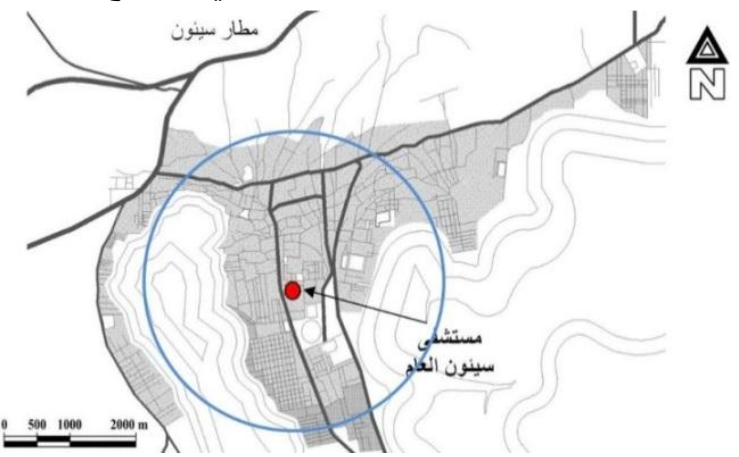

شكل(5): يوضح التقسيمات العمر انية لمدينة سيئون وموقع المستشفى المختارة فيها [14]

3.2. تحلبل احتباجات الأمن والسالامة بعستشفيات محافظة حضرموت

استهدفت الورقة البحثية التعرف على مدى توفر عناصر الأمن والسلامة في تصميم هذه النوعية من

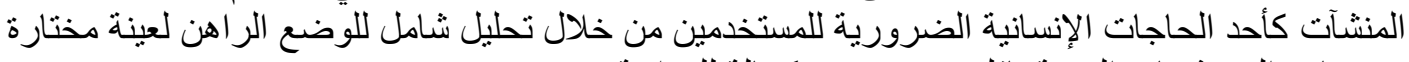
من مباني المستشفيات اليمينة بإقليم حضرموت الإنهات كحالة للار اسة.

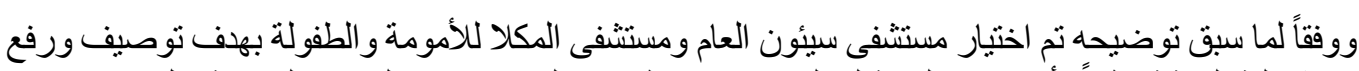

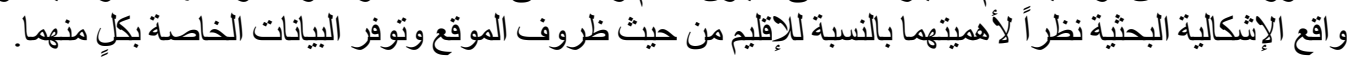




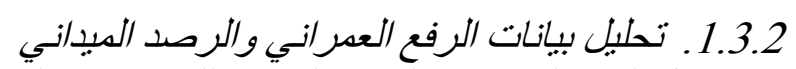

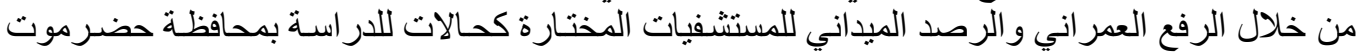

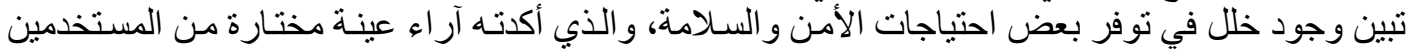

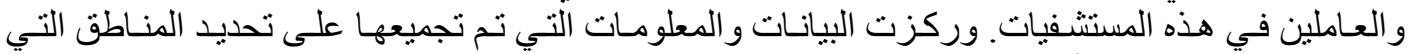
يشترط توفر احتياجات الأمن و السلامة لها، وركئ والتي تشمل:

تحديد المناطق ذات المخاطر المحتملة.

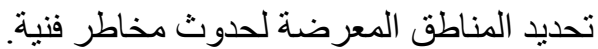

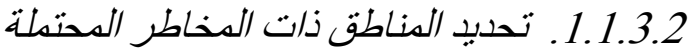

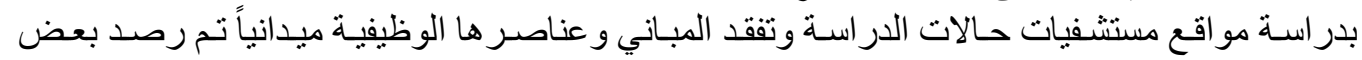

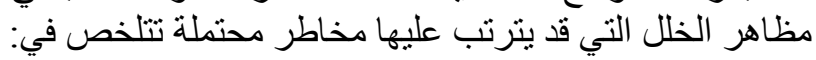

- عدم وجود نقاط للتحكم في تتقل الأفر اد و المرور عبر المداخل و المخـار ج وكذلك بين الأقسـام التخصصية

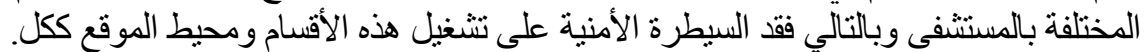

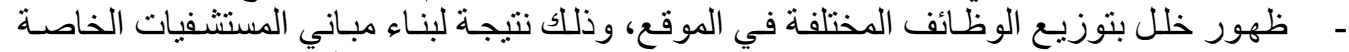

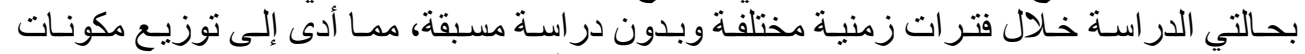

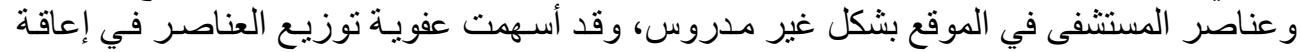

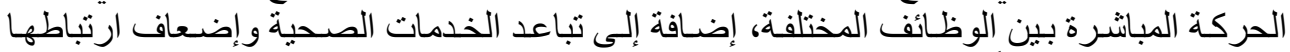

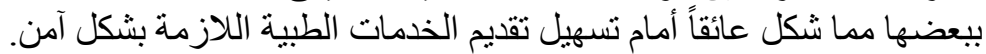

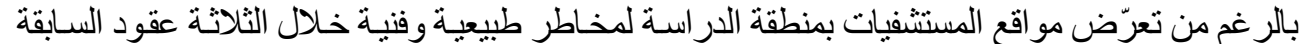

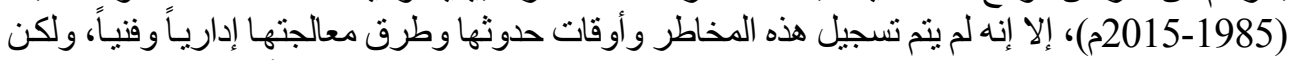

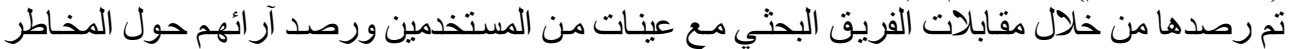

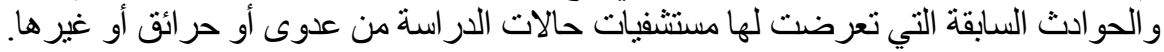

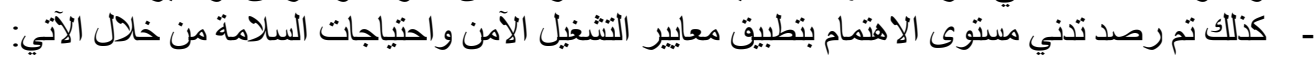

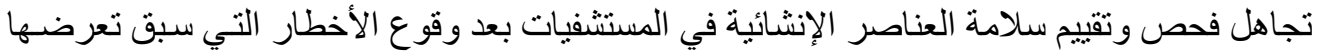

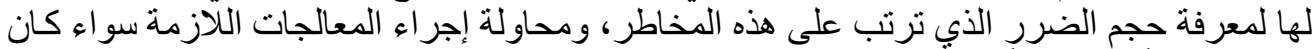

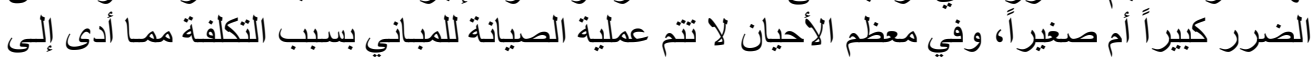

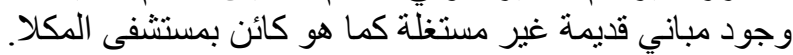

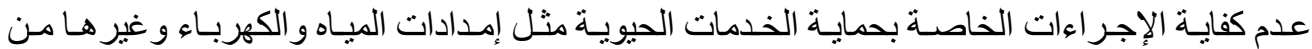

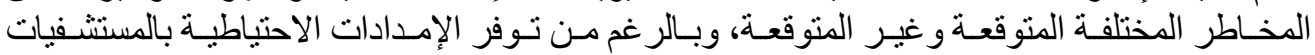

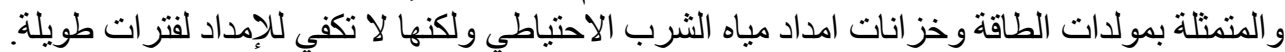

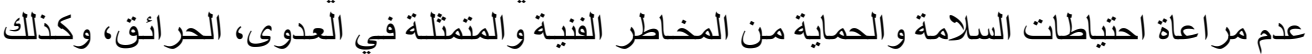

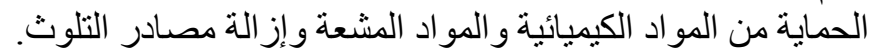

وتوضح الأشكال رقم (6)، رقم (7) تحديد المناطق ذات المخاطر المحتملة في الموقع العام لكل من العينات

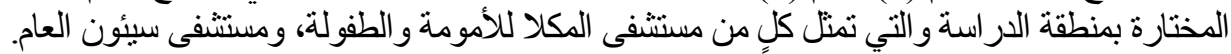

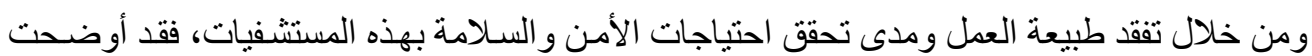

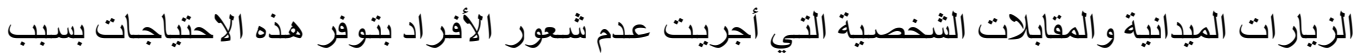

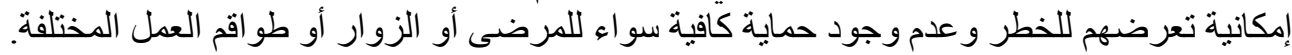




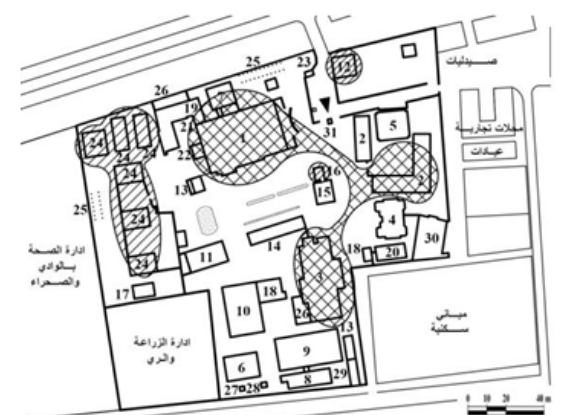

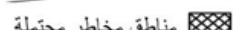

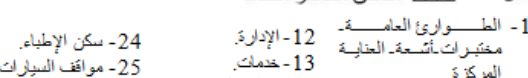

$$
\begin{aligned}
& \text { 26- 26 منطقة نمزين. } \\
& \text { 28 }
\end{aligned}
$$

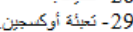

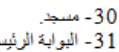

$$
\begin{aligned}
& \text { 14 - منطقة الكدماك. } \\
& \text { 15 - مكتب الإحصاء. }
\end{aligned}
$$

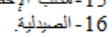

$$
\begin{aligned}
& \text { 17 - مكزن ألدوية } \\
& \text { 18 }
\end{aligned}
$$

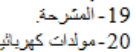

$$
\begin{aligned}
& \text { 21 - مغنلة }
\end{aligned}
$$

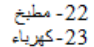

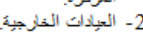

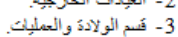

$$
\begin{aligned}
& \text { 4- مزكز الأمومة والطفنولة } \\
& \text { 5- مركز العلاج الطبيتى. } \\
& \text { 6- كزكز الأورجّم. } \\
& \text { 7- } 6 \text { - تسخبص الأورجمي. } \\
& \text { 8- مينتى الحزوق. } \\
& \text { 10 - 10 إقامة نساءة. }
\end{aligned}
$$$$
\text { 11 }
$$

شكل (7): تحديد المناطق ذات المخاطر المحتملة

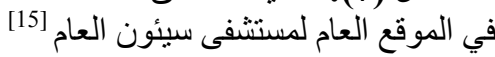

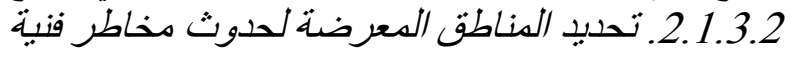

شكل (6): تحديد المناطق ذات المخاطر المحتملة

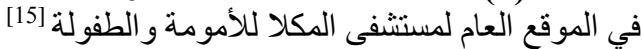

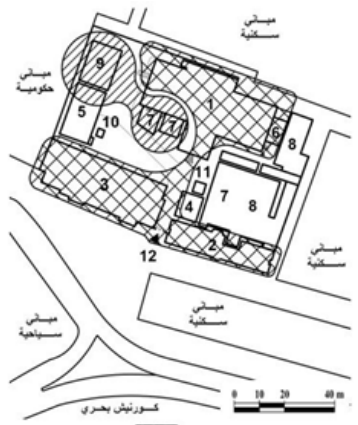

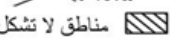

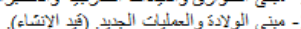

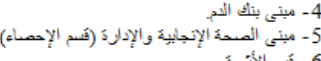

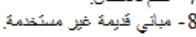

$$
\begin{aligned}
& \text { 9- مينتى الإدلاند. } \\
& \text { 10- مصنى -10 } \\
& \text { 11 - } 11
\end{aligned}
$$

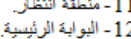

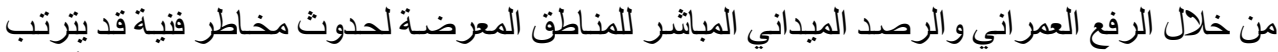

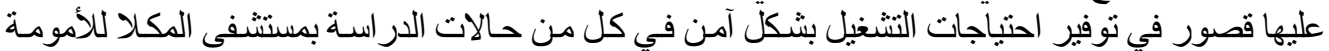

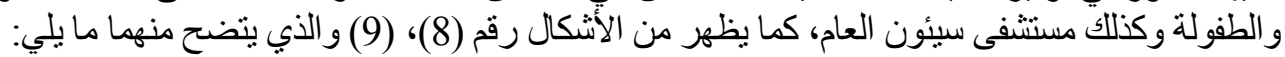
- الخلل الو اضح في اختيار موقع قسم الأشعة في مستشفى المكلا بسبب بعد المسـافة بينهـه وبين الأقسـام

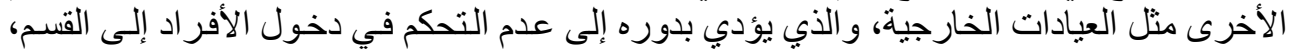

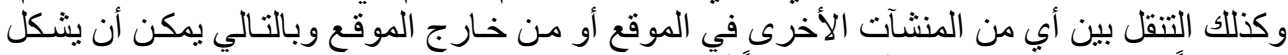

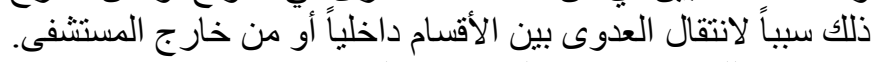

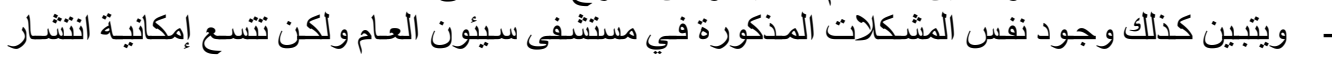

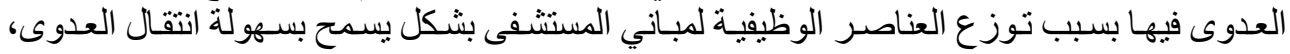

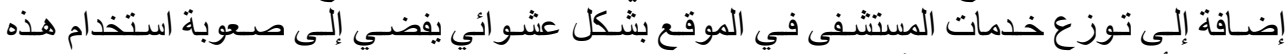

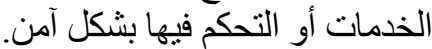

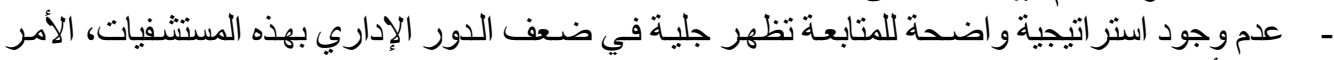

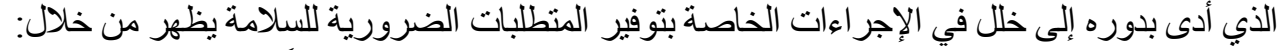

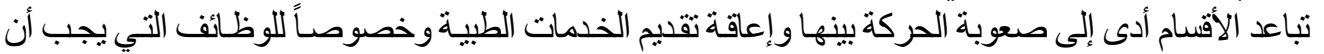

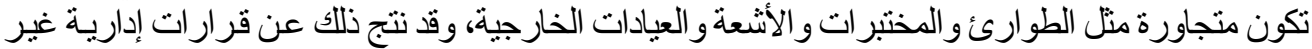

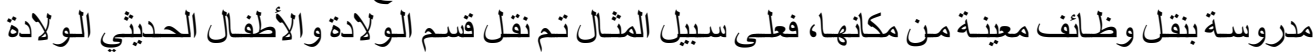

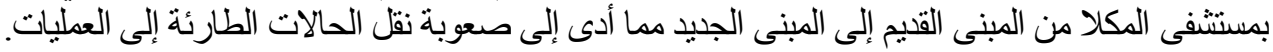

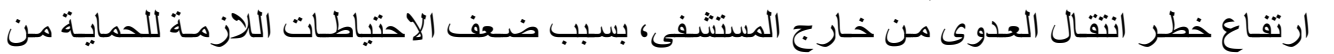

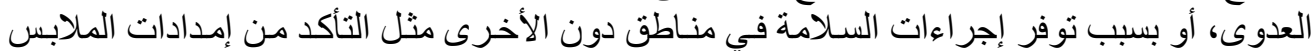

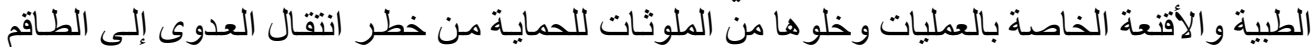

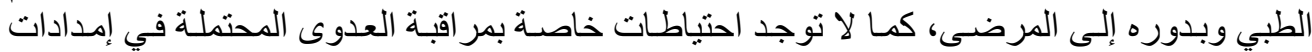

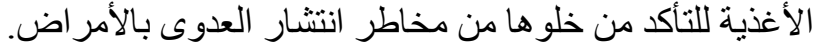


وفاء عبد الله بلمعلا و خالد محمد أحد الليثي، تحليل /حتياجات الأمن و السلامة في تصديم مباني المستشفيات .

• عدم إجر اء صيانة دورية للمباني مما يزيد من إمكانية حدوث مخاطر محتملة لعدم وجود قياسـات لتحديد

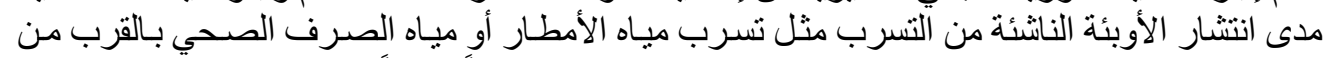

مناطق القلق، وكذلك مر اقبة الصرف الصحي الصنة إلى مناطق آمنة صحياً وبعيداً عن المناطق الحيوية.

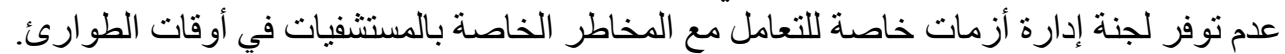

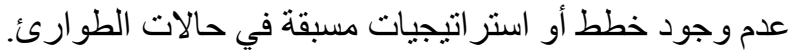

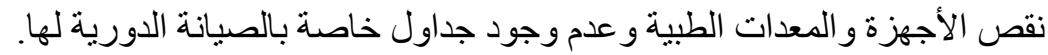

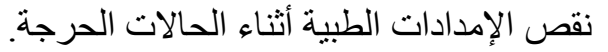
عدم توظيف الموارد المالية الملائمة لتوفير متطلبات والات احتياجات الأمن و السلامة.
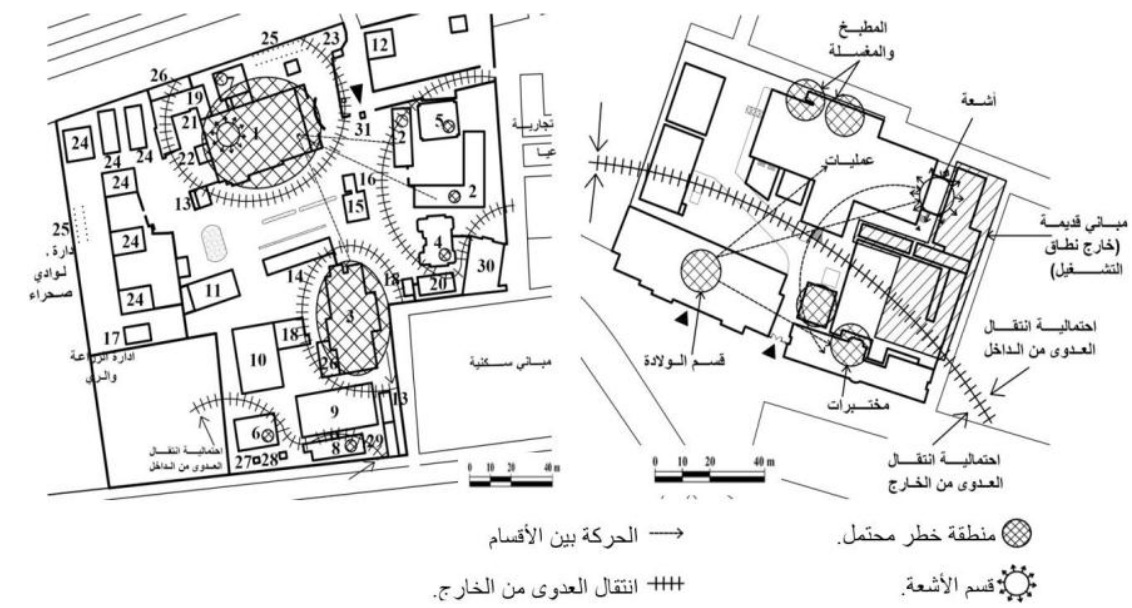

شكل (9): تحديد مناطق المخاطر الفنية المحتملة

شكل (8): تحديد مناطق المخاطر الفنية المحتملة

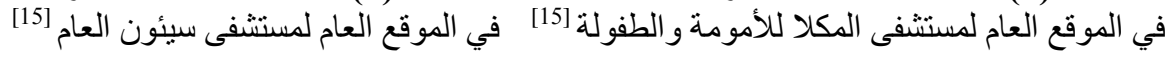

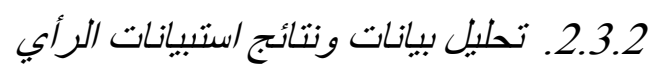

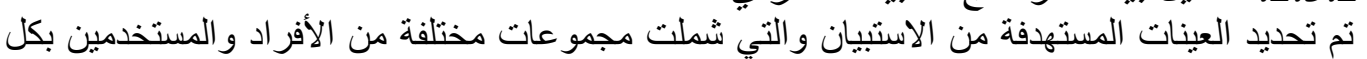

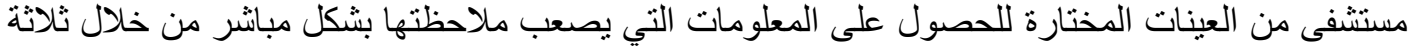

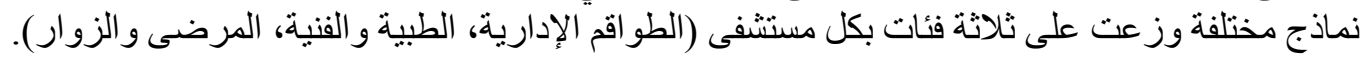

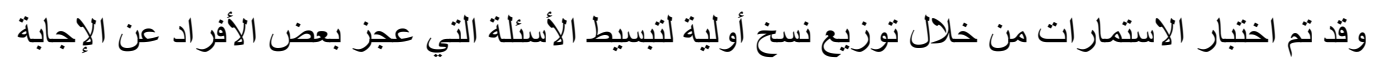

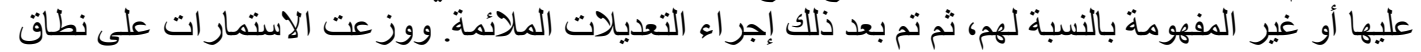

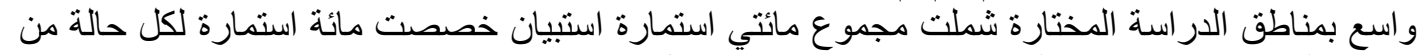

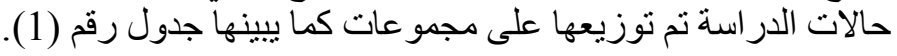
جدول رقم (1): توزيع استمار ات الاستبيان بمستشفى المكلا ومستشفى سيئون العام [16]

\begin{tabular}{|c|c|c|c|c|c|c|}
\hline \multicolumn{3}{|c|}{ مدينة سيئون (حضنتى سيئون العام/ الو ادي) } & \multicolumn{3}{|c|}{ مدينة المكلا (حضركلا للأمومة و الطفولة الساحل) } & \multirow[b]{2}{*}{ الاستمار ات } \\
\hline المرضنيان & الطنبيان الطاقم & الطتبيان & المرضنى الزوار & الطتبيان الطاقم & $\begin{array}{l}\text { الطنبيان } \\
\text { الإداري } \\
\text { الطاقي }\end{array}$ & \\
\hline \multicolumn{3}{|c|}{100} & \multicolumn{3}{|c|}{100} & إلجمالي عدد ات \\
\hline 30 & 40 & 30 & 30 & 40 & 30 & عدد الاستمار ات \\
\hline
\end{tabular}


JES, Assiut University, Faculty of Engineering, Vol. 43, No. 4, July 2015, pp. 540 - 557

\begin{tabular}{|c|c|c|c|c|c|c|}
\hline \multicolumn{3}{|c|}{ مدينة سيئون (حضتشفى سيئون العام/ الو ادي) } & \multicolumn{3}{|c|}{ 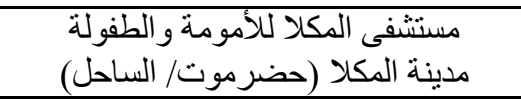 } & \multirow[b]{2}{*}{ الاستمار ات } \\
\hline المرضتبيان & الطنبيان الطاقم الفني & $\begin{array}{l}\text { الطتبيان } \\
\text { الإداري }\end{array}$ & المرضتبيان & الطنبيان الطاقم & $\begin{array}{l}\text { الطتبيان } \\
\text { الإداري }\end{array}$ & \\
\hline 22 & 40 & 30 & 27 & 38 & 28 & عدد الاستمار ات \\
\hline 8 & 0 & 0 & 3 & 2 & 2 & عدد الاستمار ات \\
\hline
\end{tabular}

و واستهف الاستيان التحقق من مدى تطييق احتيلجات الأمن و السلامةوبيان فعالية الإدارةودورهافي تطييقوتحقيق الإجراءات

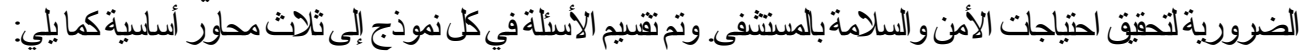

$$
\text { • مدى تطبيق معايير الأمن: و التي يستشف منها شعور الأفر اد بالأمان بالمستشفى. }
$$

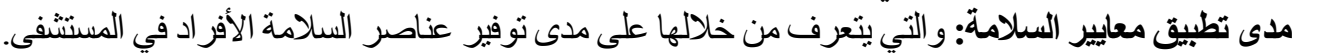

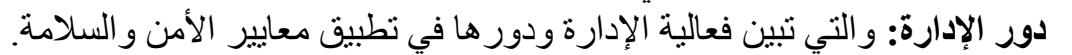

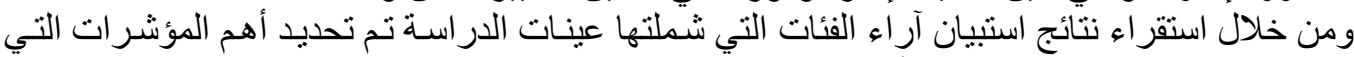

تسهم في قياس مدى تحقق احتياجات الأمن و السلامة في مستشفيات منطقة الدراسة في في النقات النقاط التالية:

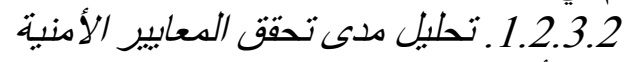

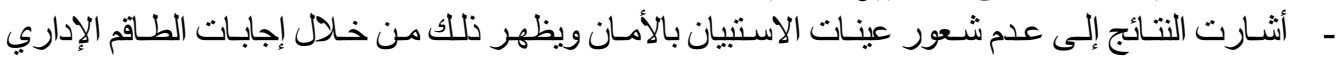

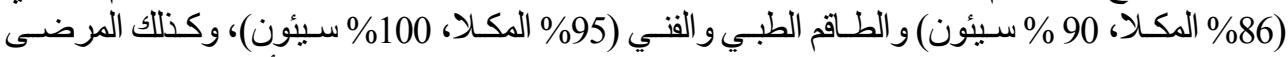
و الزوار (78 \% المكلا، 86\% سيئون)، حيث تتركز الَّماية في التحقق من دخول الأفراد و السيارات فقط.

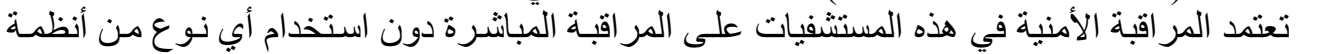

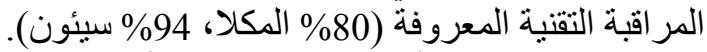

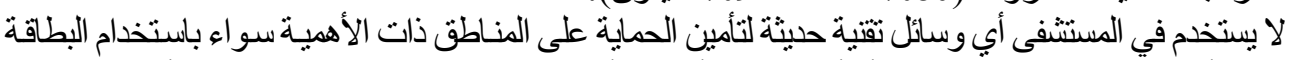

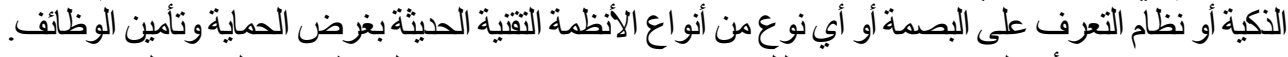

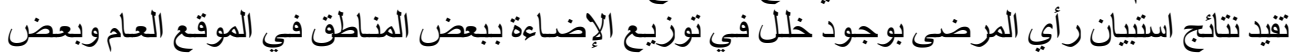

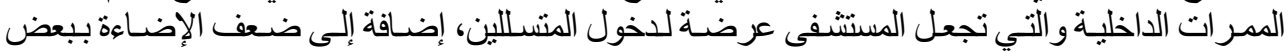

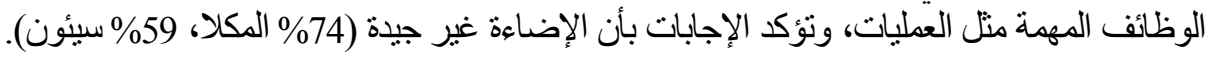

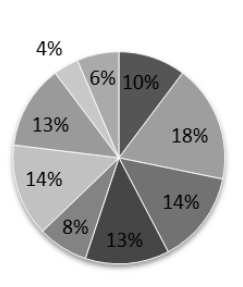

مستثشى سيئون العام

[15]
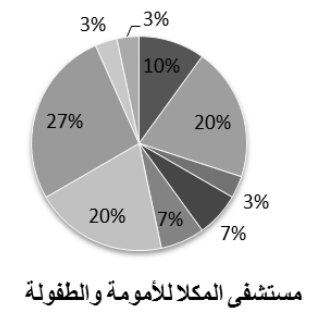

مستثفى المكلا للأمومة و الطقولة

صماية المناطق الحيوية

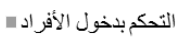

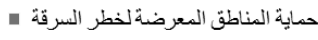

- تجهيز الأبوابو والنو افذبماية أمنية

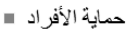

|" التحكم بمرور السبار ات ضمن الحد الأدنى

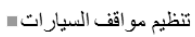

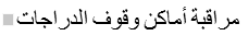

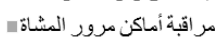

شكل (10):
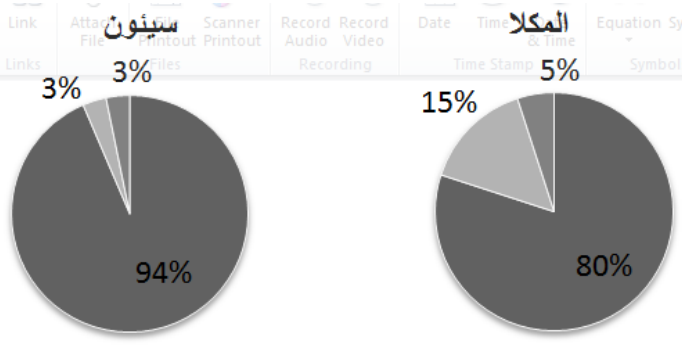

نظام المر اقبة المبانشرة."

شكل (11): النسبة المئوية لنتائج نوع نظام المر اقبة المستخدم [15]

- Closed Circuit Television (CCTV

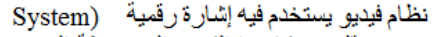

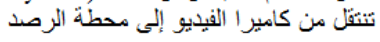

- Automatic Number Plate Recognition نظام لتحديد أرقام لوحسة (ANPR System) النبار ات بالبو ابات الرئيسية 
وفاء عبد الله بلمعلا و خالد محمد أحد الليثي، تحليل احتياجات الأمن و السلامة في تصديج مباني المستشفيات .

- أكدت نتائج استنيان رأي الطـاقم الإداري تركز الحمايـة على منـاطق معينـة منـل منـاطق البو ابـات الرئيسية

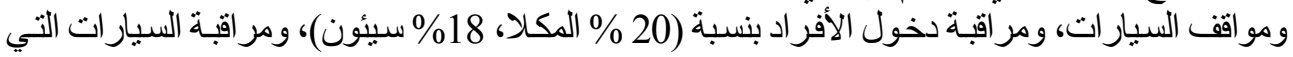
تمر من خلال البو ابة الرئيسة بنسبة (20\% المكلا، 14\% سيئون) وضعف هذه الحماية في باقي المناطق.
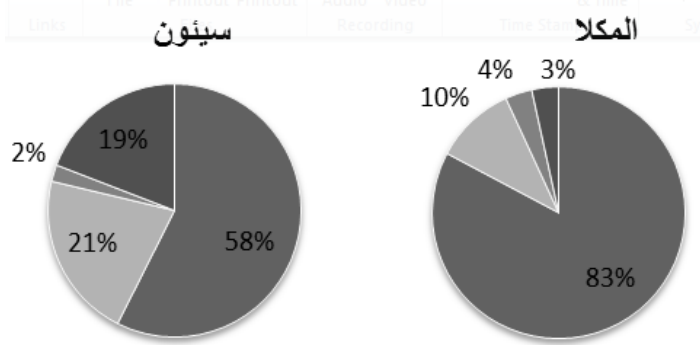

مناطق الدخول / الخروج

شكل (12): مقارنة نتائج المناطق ذات الأولوية بالرفابة في المسنشفيات [15]

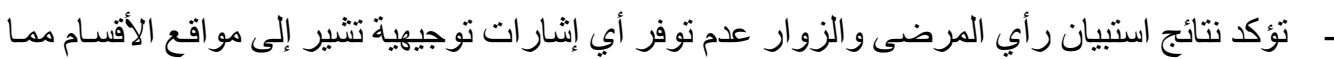

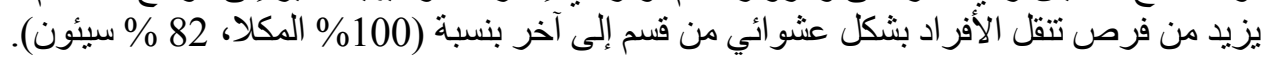

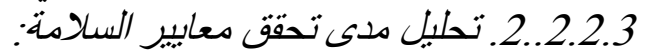

تشير النتائج إلى تعرّض المسنتفى لمخاطر فنية سابقة مثنل الأمطار و العدوى وغير هـا، ومـع ذلك لم يتم اتخاذ التدابير اللازمة للحماية ويلاحظ لهن الآتي:

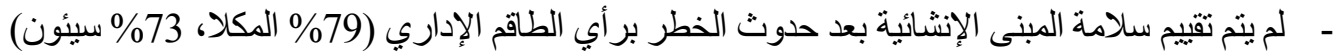

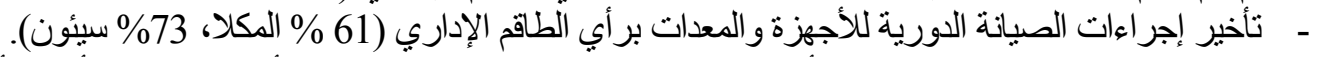

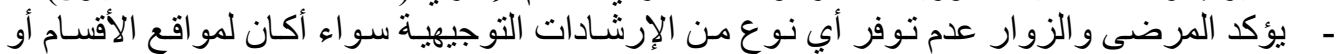

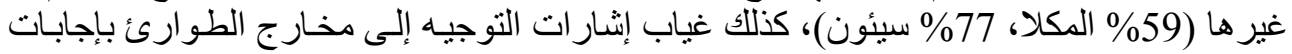

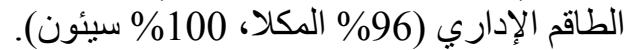

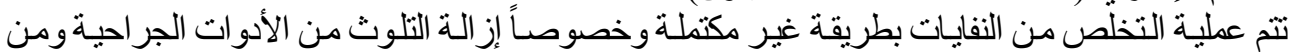

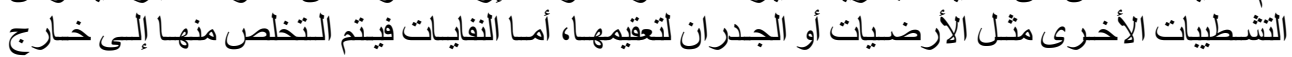

المستشفى بطريقة جيدة من وجهة نظر الطاقم الإداري (50\% بمسنتفى المكلا، 41\% بمستشفى سيئون).

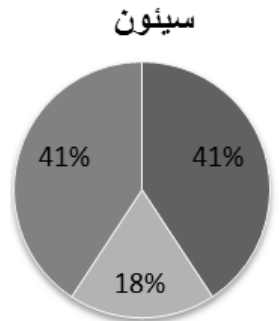

المكلا

شكل (13): نتائج إجر اءات الحماية من العدوى في الأقسام [15]

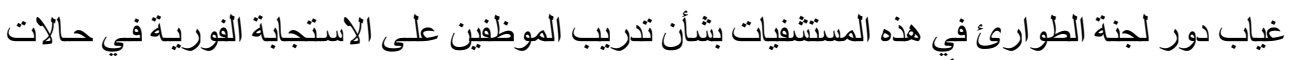

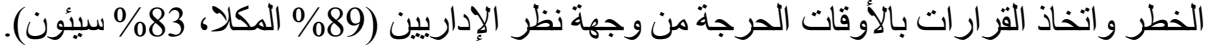

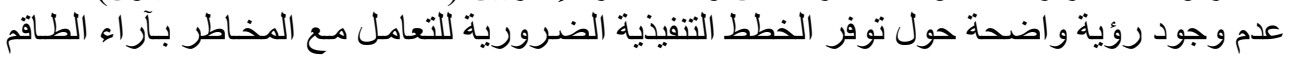

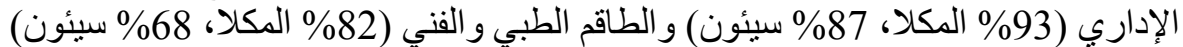

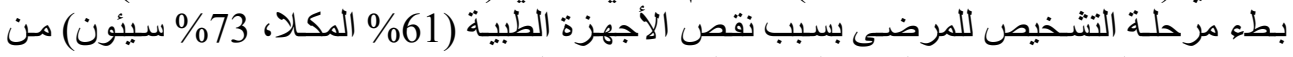

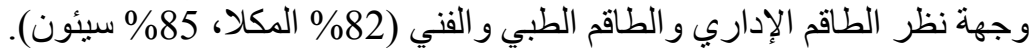

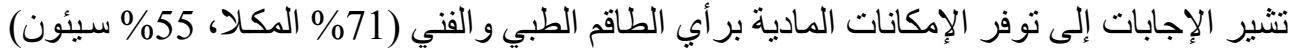
إلا إنه لا يوجد ترشيد لاستخدام هذه الموارد الإن بشكل صحيح. 
- - تظهر نتائج استبيان رأي الطاقم الطبي و الفني اهتماماً بتوفير الأنظمـة الحيويـة مثنل المساء و الكهربـاء

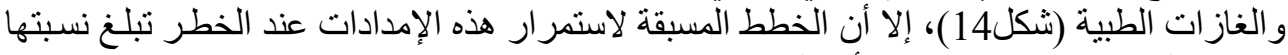

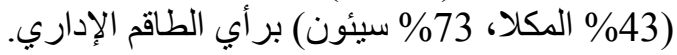

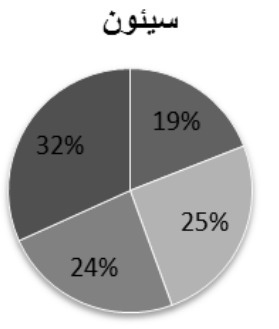

المكلا

شكل (14): مقارنة نتائج توفر مخزون الإمدادات الأساسية في المستشفيات [15]

3.2.2.3. تحلبيل مدى تحقق فعالبة الإدارة

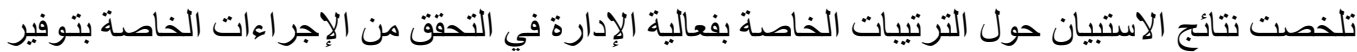

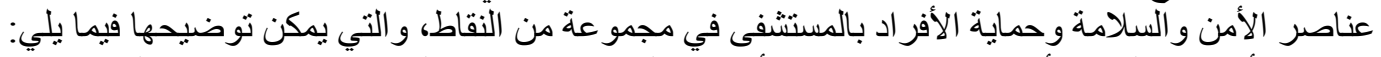

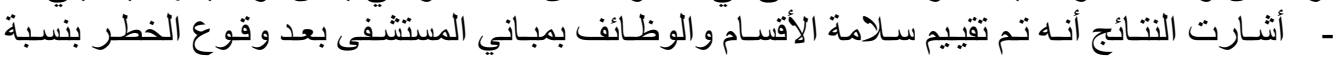

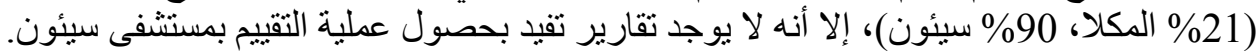

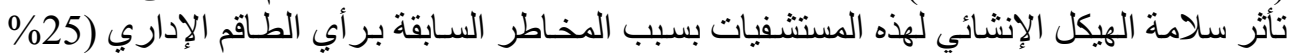

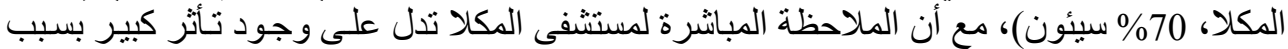

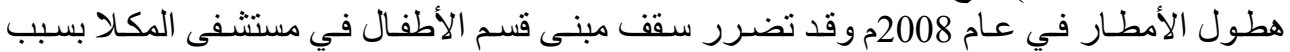

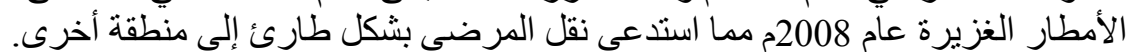

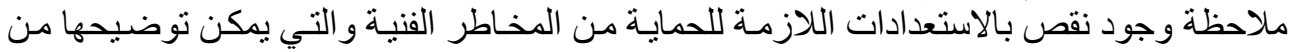

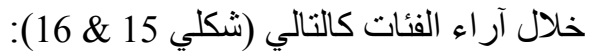

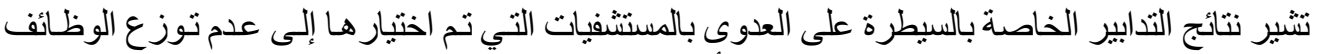

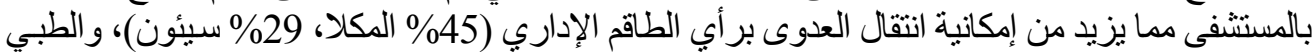

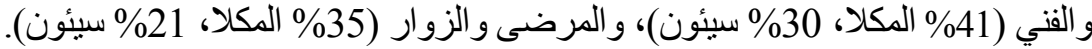

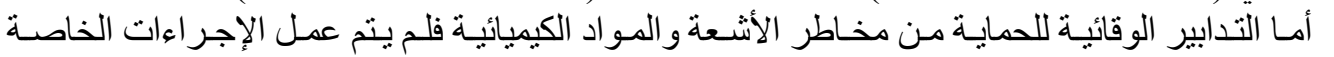

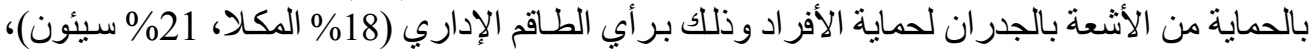

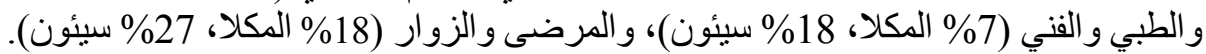

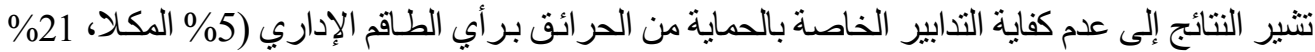

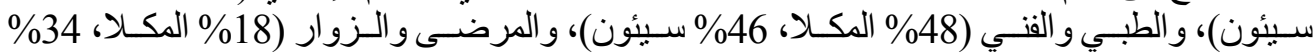

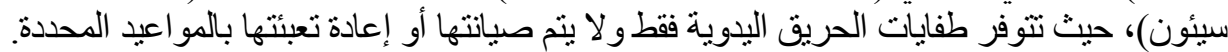

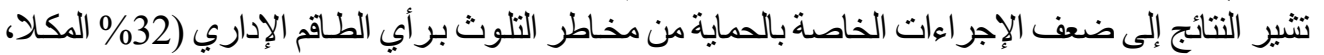

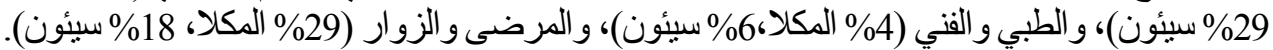

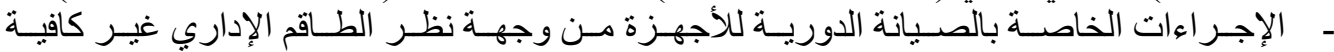

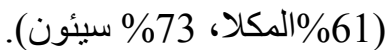
- ـتجه نتائج استبيان رأي الطاقم الطبي و الفني إلى الإيجابية عند سؤ الهم عن توقعهم لاستمر ار تقديم

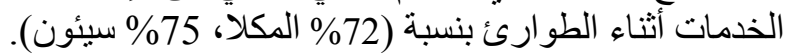

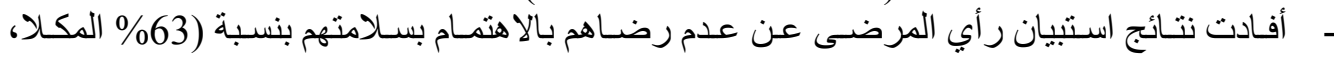

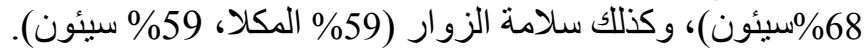

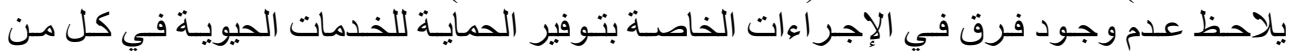

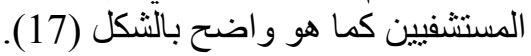




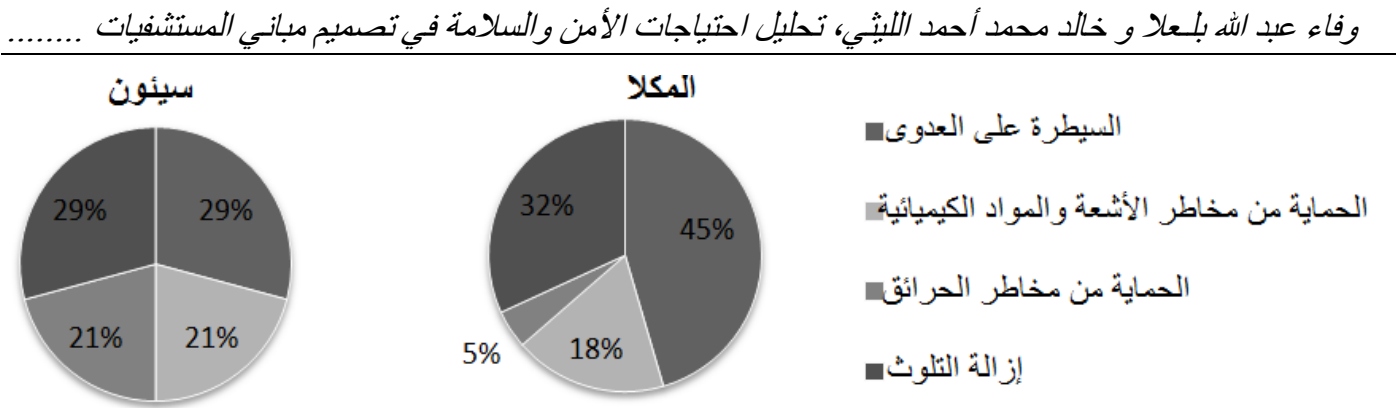

شكل (15): نتائج استبيان رأي الطاقم الإداري حول التدابير الوقائية للحماية من المخاطر الفنية [15]
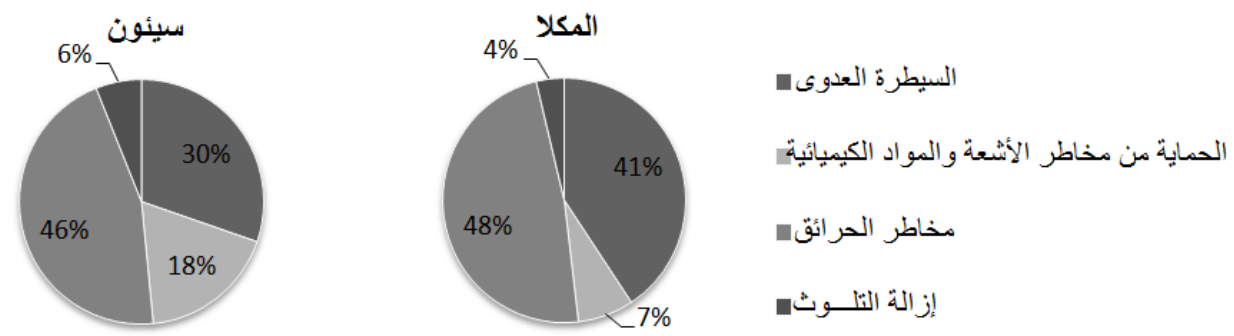

شكل (16): نتائج استبيان رأي الطاقم الطبي و الفني حول التدابير الوقائية للحماية من المخاطر الفنية [15]

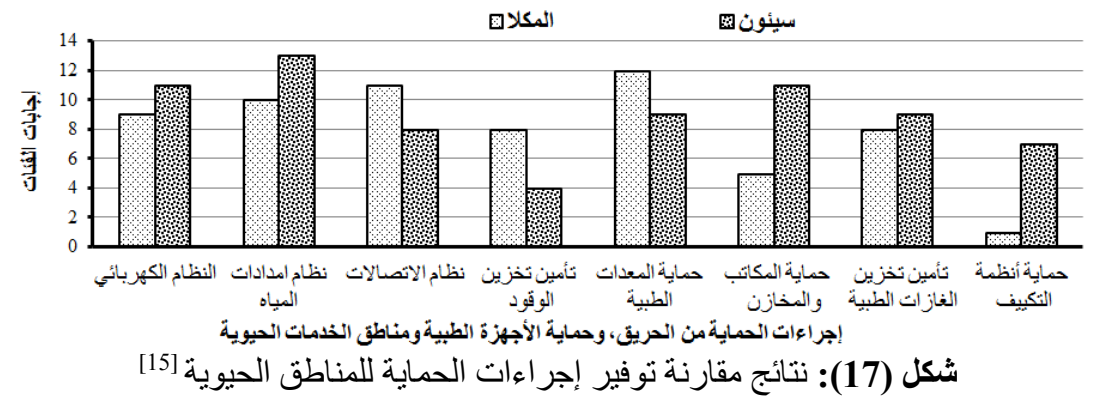

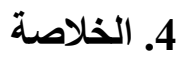

عرضت الورقة البحثية أهمية توفر احتباجات الأمن و السـلامة كأحد المعايير الأساسية لتصميم وتشـغيل مباني

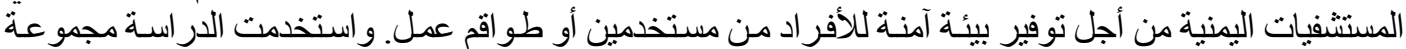

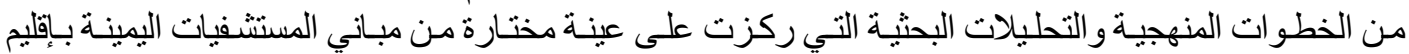

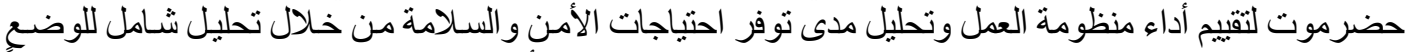

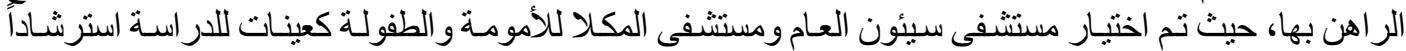

بمعايير الأمن و السلامة المدرجة من قبل منظمة الصحة العالمية (World Health Organization-WHO).

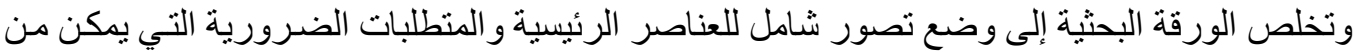

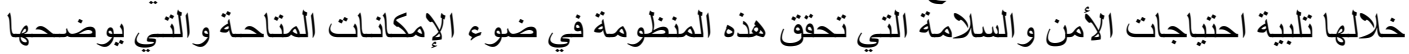

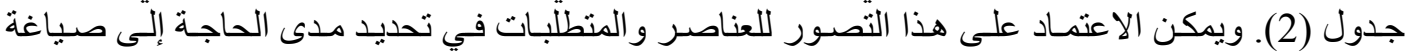
تفصيلية لتفعيل عناصر هذه المنظومة في المستشفيات اليمينة بما يتلاءم مع الظروف المحلية لمنطقة الدر اسة. 
JES, Assiut University, Faculty of Engineering, Vol. 43, No. 4, July 2015, pp. 540 - 557

جدول رقم (2): للعناصر الرئيسية والمنطلبات الضرورية لتلبية احتياجات الأمن و السلامة الملائمة للبيئة اليمنية [16]

\begin{tabular}{|c|c|c|c|c|c|c|c|c|c|}
\hline \multicolumn{4}{|c|}{ مستشفى سيئون } & \multicolumn{4}{|c|}{ مستشفى المكلا } & \multicolumn{2}{|l|}{ 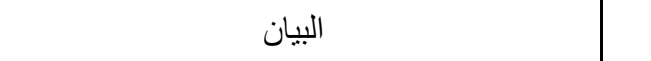 } \\
\hline 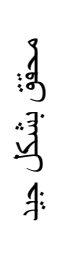 & 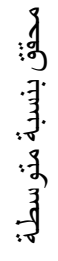 & 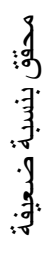 & वें & 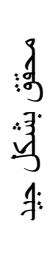 & 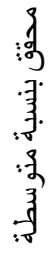 & 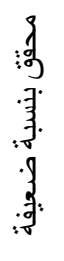 & 里: & الضرورية لعمل منظومة والمنطلبات & 司: \\
\hline$\frac{0}{2}$ & $\frac{0}{\grave{o}}$ & $\begin{array}{l}0 \\
\frac{1}{1} \\
\text { mo } \\
0\end{array}$ & $\begin{array}{l}\frac{1}{2} \\
\frac{1}{0} \\
0\end{array}$ & $\begin{array}{l}\text { 잉 } \\
\frac{1}{0} \\
0\end{array}$ & 官 & $\begin{array}{l}0 \\
\text { 1 } \\
\text { ֻे } \\
0\end{array}$ & $\frac{h_{1}^{2}}{0^{1}}$ & 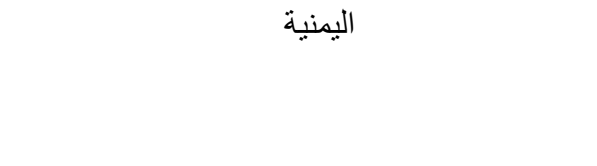 & 牙. \\
\hline & & & $\bullet$ & & & & $\bullet$ & حماية الأفر اد (المرضى، الزوار، الطو اقم الفنية والإدارية) & \\
\hline & & & $\bullet$ & & & & $\bullet$ & حماية المناطق الحيوية & \\
\hline & & • & & & & & $\bullet$ & حماية المناطق ذات أولوية قصوى في المرفق الصحي & \\
\hline & & $\bullet$ & & & & & • & التحكم و اللبيطرة على نقاط المداخل و المخارج و التتقل & $\bar{f}$ \\
\hline & & & $\bullet$ & & & & $\bullet$ & نوع نظام المر اقبة بالمستشفيات & $\exists$ \\
\hline & & & $\bullet$ & & & & $\bullet$ & تأمين الحماية باستخدام الوسائل التكنولوجية & \\
\hline & & & $\bullet$ & & & & $\bullet$ & تأمين الحماية باستخدام الأنظمة الأمنية & .3 \\
\hline & & $\bullet$ & & & & & $\bullet$ & توفير الإشار ات التوجيهية لتسهيل الحركة & \\
\hline & • & & & & & $\bullet$ & & 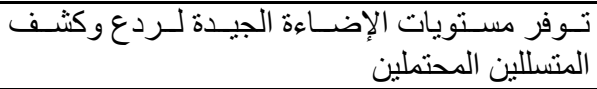 & \\
\hline & & $\bullet$ & & & & e & & التحكم بدخول الأفر اد للمنشأة الصحية & \\
\hline & e & & & & & e & & حماية الموقع العام من المخاطر (طبيعية / فنية) & \\
\hline & & $\bullet$ & & & & $\bullet$ & & حماية الهيكل الإنشائي للمباني & \\
\hline & - & & & & $\bullet$ & & & تأمين التر ابط الوظيفي بين الأققسام & \\
\hline & & & $\bullet$ & & & & $\bullet$ & تجميع الوظائف ذات المخاطر المحتملة & $\bar{A}$ \\
\hline & & $\bullet$ & & & & & $\bullet$ & الحماية من مخاطر الحرائق & 马: \\
\hline & & $\bullet$ & & & & $\bullet$ & & حماية الأفر اد من الأشتعة و المو اد الكيميائية & \\
\hline & - & & & & - & & & السيطرة على العدوى & $\overline{3}$ \\
\hline & $\bullet$ & & & & $\bullet$ & & & التخلص من النفايات & 3 \\
\hline & $\bullet$ & & & & - & & & إز الة التلوث من الأدوات الجر احية & \\
\hline & & $\bullet$ & & & & 는 & & توفير الأجهزة الطبية & \\
\hline & & $\bullet$ & & & & e & & توفير المواد و الأدوات الطبية & \\
\hline & & & $\bullet$ & & & & $\bullet$ & تشكيل لجنة للتعامل مع حالات الطو ارئ & \\
\hline & & & $\bullet$ & & & & $\bullet$ & إعداد خطط الإنقاذ و الإخلاء & \\
\hline & & & $\bullet$ & & & & $\bullet$ & تحديد استر اتيجية التعامل مع المخاطر & \\
\hline & & & $\bullet$ & & & & $\bullet$ & تدريب العاملين & : \\
\hline & & & $\bullet$ & & & & $\bullet$ & التعامل معهي عند الأفر اد بالمخـاطر المحتملة وكيفية & $\frac{7}{3}$ \\
\hline & $\bullet$ & & & & & $\bullet$ & & تأمين توفير وتشغيل الأنظمة الحيوية & .7 \\
\hline & & $\bullet$ & & & & $\bullet$ & & تطبيق إجر اءات الصيانة الدورية للمباني & \\
\hline & & $\bullet$ & & & $\bullet$ & & & تطبيق إجر اءات الصيانة الدورية للاجهزة الطبية & \\
\hline & & $\bullet$ & & & & $\bullet$ & & توفير الموارد المالية اللازمة لتطبيق احتياجات السلامة & \\
\hline
\end{tabular}




\section{5 5 النتائج والتوصيات}

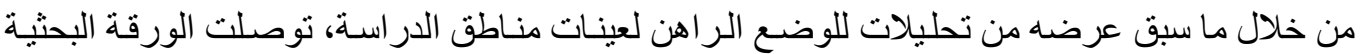

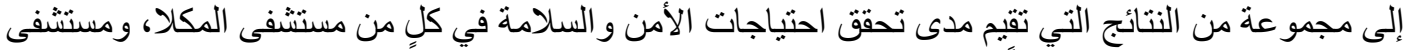

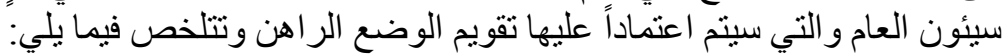
1.5 النتائج

تبين وجود خلل بتلبية احتياجات الأمن و السلامة بمستشفيات محافظة حضرموت و والذي أثنارت إليه نتائج آراء المستخدمين و العاملين في هذه المستشفيات، و المنمنلة في:

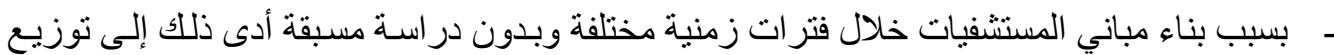

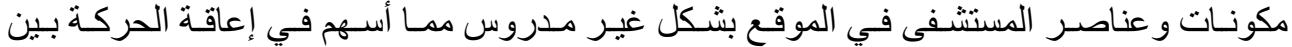

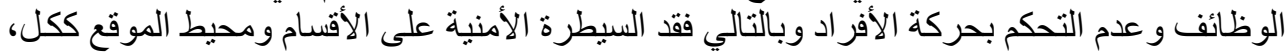

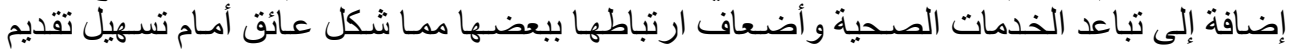

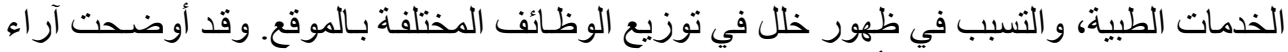

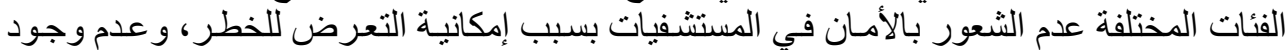
حماية كافية للمرضى و الزوار أو العاملين، كما يتضح من الثكل التالي:

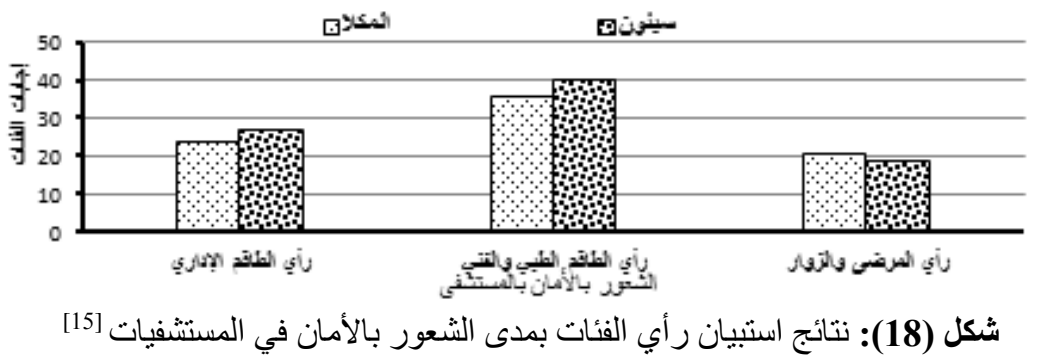

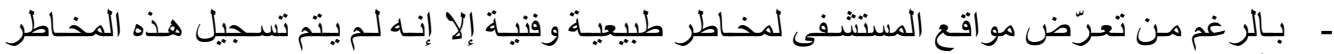

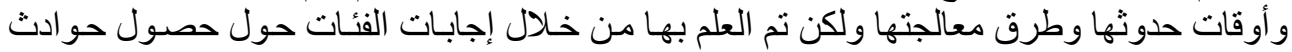

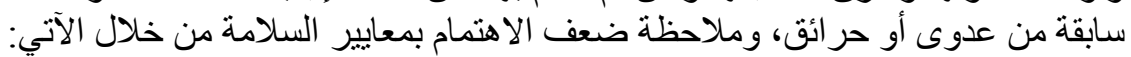

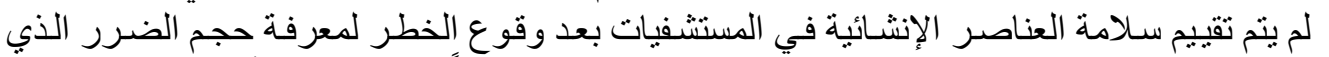

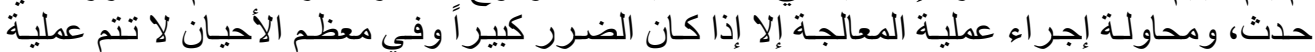

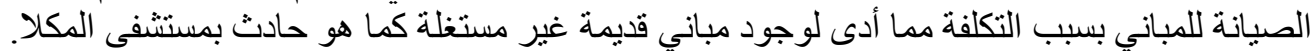

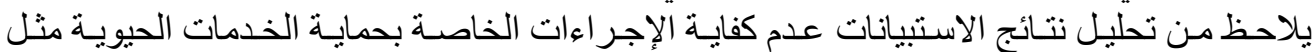
إمدادات المياه و الكهرباء و غيره من الأنيات المخاطر المختلفة.

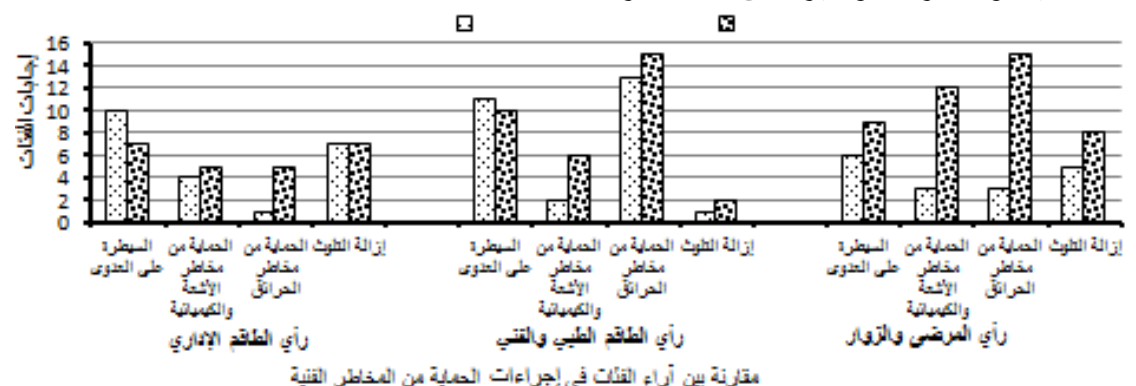

شكل (19): آراء الفئات حول نقص الاستعداد اللازمة للحماية من المخاطر الفنية في المستشفى [15]

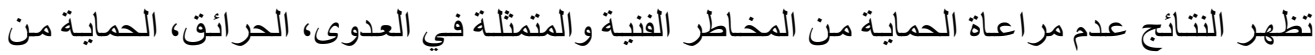
المواد الكيميائية و المشعة وإز الة التلوث و وغير ها، شكل رقم (19). 
- ضعف الدور الإداري في هذه المستشفيات أدى إلى خلل في الإجراءات الخاصـة بتوفير المتطلبـات

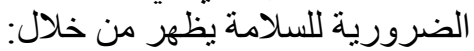

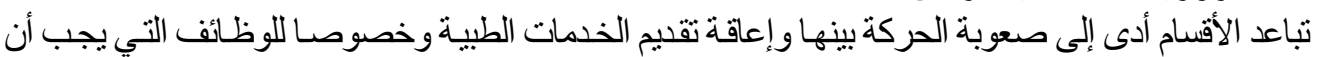

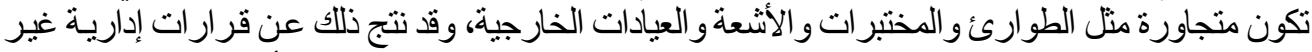

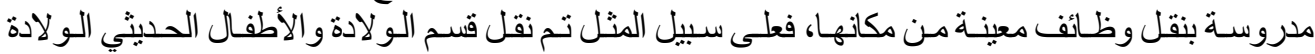

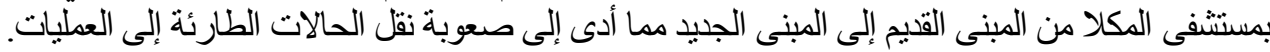

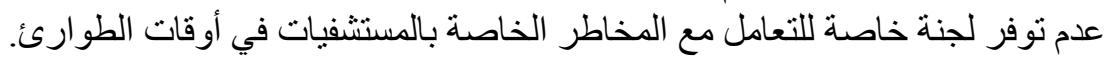

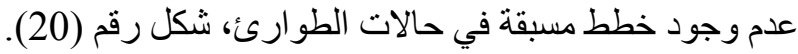

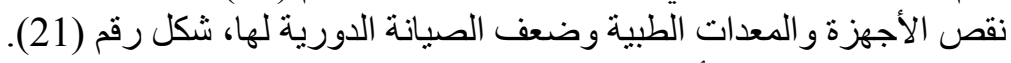
نقص الإمدادات الطبية أثناء الحالات المعات الحرجة. عدم توظيف الموارد المالية لتوفير متطلبات الألمات الأمن والسلامة.
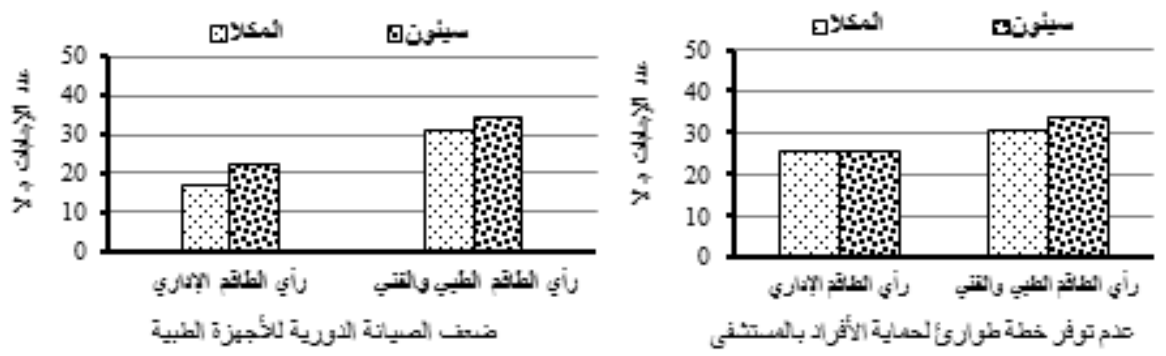

شكل (20): ر أبي (الطاقم الطبي و الفني/الطاقم الإداري) شككل (21): رأي (الطاقم الإداري/ الطاقم الطبي و الفني)

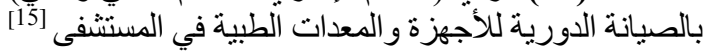
بخطة الطوارئ في ألمستشفى (20) 2.5. التوصبات

يظهر من النتائج السابقة قصور و اضح في تطبيق معايير الأمن و السلامة بالمستشفيات التي أجريت عليها

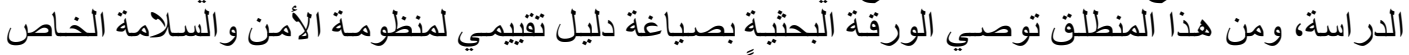

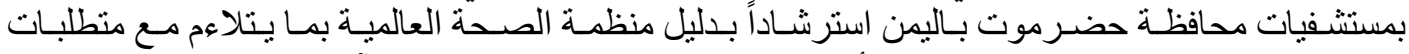

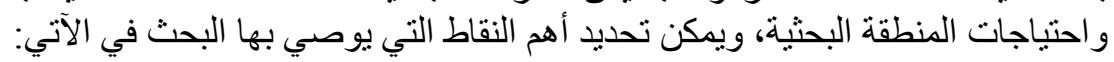

- وضع تصور شامل للعناصر الرئيسية والمتطلبـات الضرورية التي يمكن من خلالها تلبية احتياجـات الأمن

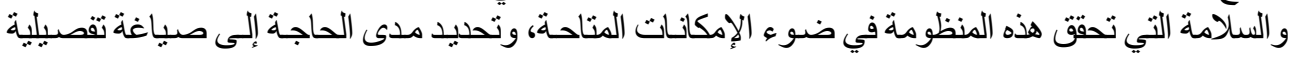

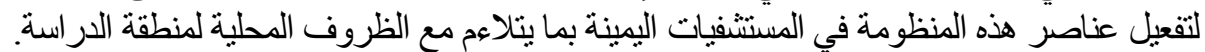

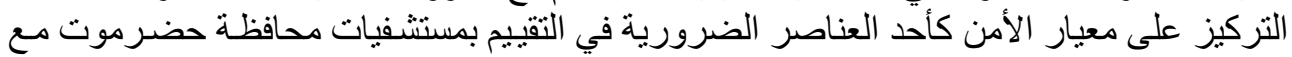

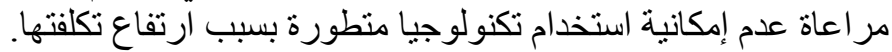

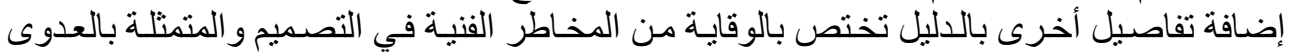

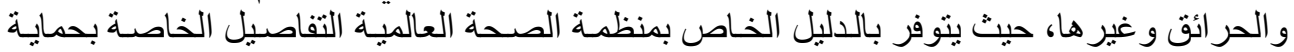

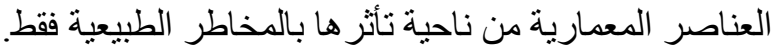

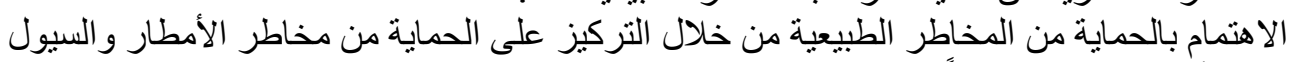
كونها أكثر المخاطر حدوثاً بمنطقة الدر اسة البر البحثنية.

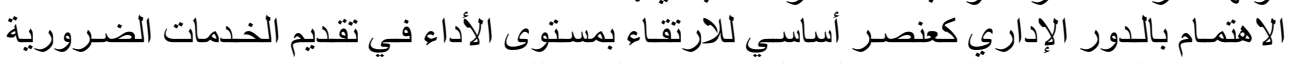

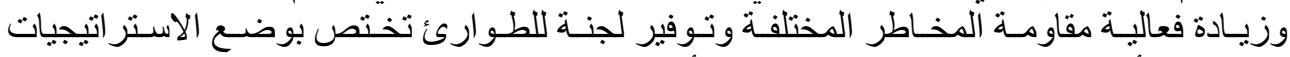

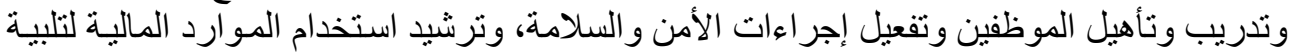

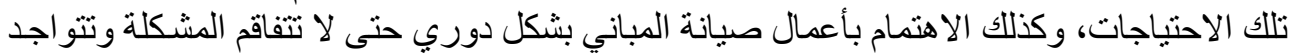
مباني متضررة لا يمكن استغلالها كما هو حادث بمستشفى الأفى المكلا. 
وفاء عبد الهه بلعلا و خالد محد أحدد الليثي، تحليل /حتياجات الأمن و السلامة في تصميم مباني الدستشفيات ..

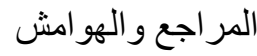

[1] ECRI Institute, (2008): “Healthcare Risk Control Security”, Reprinted with permission from Duke University Police Department, North Carolina, USA.

[2] Miehl, F., (2011): “Hospital security strategies”, Journal of healthcare protection \& management publication, the International Association for Hospital Security, Washington, USA.

[3] The Association of Chief Police Officers (2005): “Secured by Design Hospitals", London.

[4] World Health Organization, (2004): “Guidelines for Seismic Vulnerability Assessment of Hospitals”, National Society for Earthquake Technology (NSET), Nepal.

[5] World Health Organization \& Pan American Health Organization (PAHO), (2008): “Hospital Safety Index Guide for Evaluators”, Washington DC@ Pan American Health, USA.

[6] Mostafa Abdelgeleel Hussein, (2007): “47th Directing Council” \& "58th Session of The Regional Committee”, Master Degree, Architectural Department, Cairo University-faculty of Engineering.

[7] World Health Organization \& Regional Office for the Western Pacific, (2009): "Safe Hospitals in Emergencies and Disasters", Project supported by the European Commission through its Humanitarian Aid department.

[8] World Health Organization, (2004): “Guidelines for Seismic Vulnerability Assessment of Hospitals”, National Society for Earthquake Technology -Nepal (NSET), Nepal.

[9] وفاء عبداله عبدالرب بلعلا، (2009): "الاعتبارات التصميمية لمستشفيات صحة المر أة بالمدان اليمنية"،

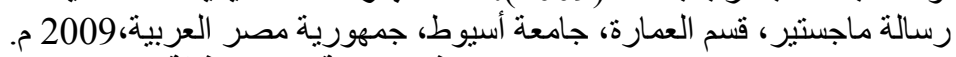

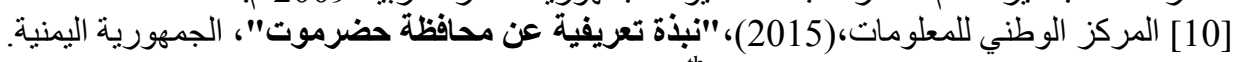

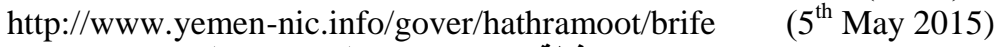

[11] المركز الوطني للمعلومات،(2015)،"التقسيم الإداري لمحافظة حضرموت"، الجمهورية اليمنية.

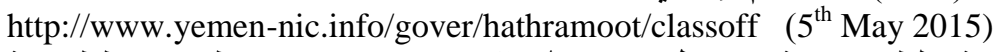

[12] مكتب وزارة الأشغال العامة و الطرق، "مشروع تطوير مدن الموانئ (2003-2005)"، تطوير مخطط مدينة

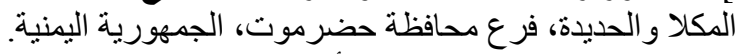

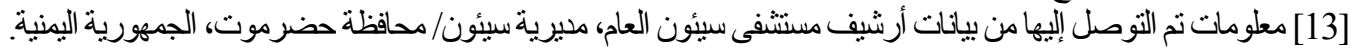

[14] خر ائط توضيحية قام الفريق البحثي بإعدادها بالاستعانة بمو اقع (Google Maps \& Google Earth).

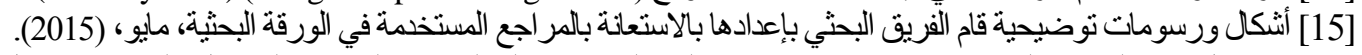

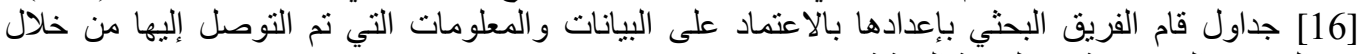

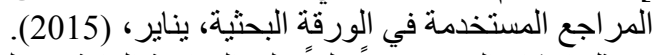

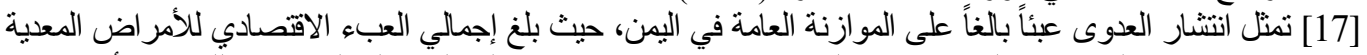

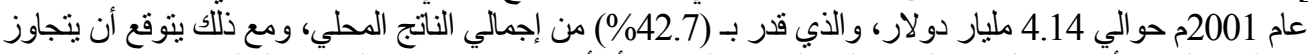

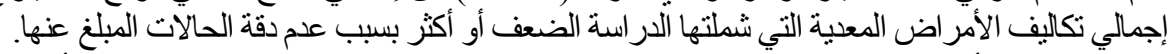

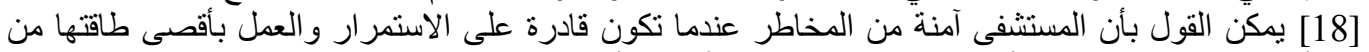

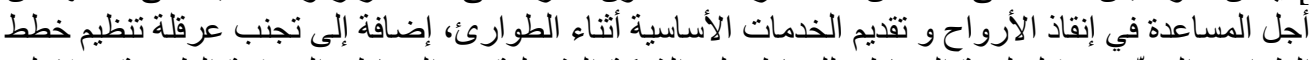

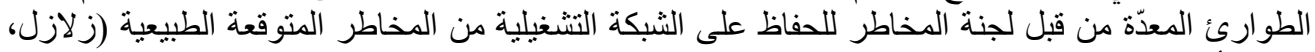

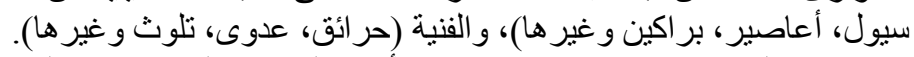

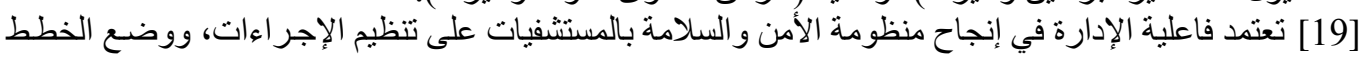

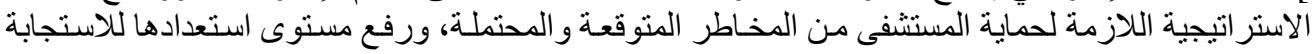

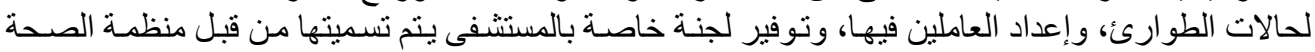

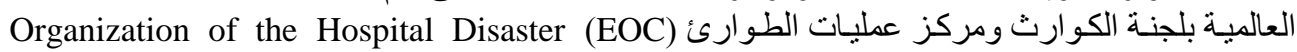

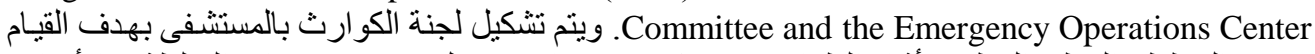

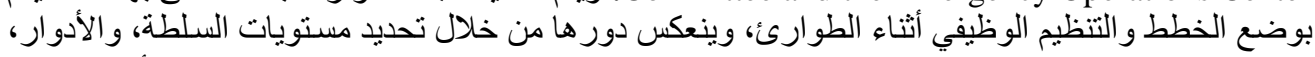

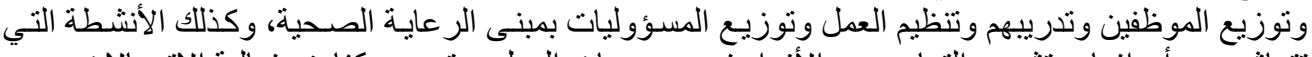

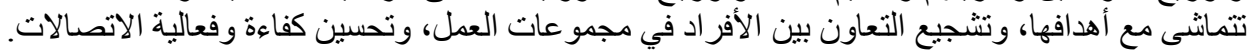




\title{
ANALYSIS OF SECURITY NEEDS AND SAFETY IN THE DESIGN OF HOSPITAL BUILDINGS IN YEMEN (CASE STUDY OF HOSPITALS IN HADRAMOUT)
}

\begin{abstract}
This paper discusses the importance of providing security and safety needs as one of the main elements that underpin the design and function of health care facilities and provides a safe environment for individuals of users or work crews. In general, health facilities counted as the arteries, which supply societies with life, especially in times of emergency and crisis. Through the review of studies and analysis of some hospital buildings designs in Yemen, some indicators that suggest a defect in the functioning of labor system in providing security needs and safety of this type of facilities, which in turn negatively affects the safety of individuals from patients or visitors, as well as various medical, technical or administrative work crews.
\end{abstract}

The aim of this paper is to analyze the status of selected sample of Yemen's hospitals buildings in Hadramout. Seyoun General Hospital (in Seyoun), and Mukalla hospital for Maternal and Children (in Mukalla) selected as samples for the study in order to identify the availability of security and safety in the design of these hospitals as one of the essential humanitarian needs of the users guided by security and safety standards listed by the World Health Organization.

This paper, through these analyses, tries to determine the defects and analyze the problems that resulted from the failure of some these basic requirements that will ensure the safety of users and verify a sense of safety in these kinds of facilities. Accordingly, recognize the most important system elements appropriate to the environment in Yemen, according to local conditions and available requirements (human, technical, technology, etc.).

This paper Concludes to develop a comprehensive conception of the main elements and necessary requirements, which can meet the needs of verifying the system in available resources, and determine the need for a detailed formulation to activate the elements of this system in hospitals of Yemen in line with local conditions of the study area.

Keywords: Security and safety, design of hospitals, health facilities, Hadramout, World Health Organization. 